\title{
Explaining serial crowdfunders' dynamic fundraising performance
}

\author{
Ahmed Sewaid $^{\text {a }}$, Simon C. Parker ${ }^{\text {b,c, }}$, Abdulkader Kaakeh ${ }^{\text {d }}$ \\ a Insper Institute of Education and Research, Rua Quatá, 300 - Vila Olímpia, 04546-042 São Paulo SP, Brazil \\ ${ }^{\mathrm{b}}$ Ivey Business School, Western University, 1255 Western Rd, London, ON N6G ON1, Canada \\ ${ }^{\mathrm{c}}$ University of Aberdeen, MacRobert Building, King's College, Aberdeen AB24 5UA, United Kingdom \\ ${ }^{\mathrm{d}}$ Utrecht University School of Economics, Utrecht University, the Netherlands
}

\section{A R T I C L E I N F O}

\section{Keywords:}

Serial crowdfunding

Finance

Funds raised

Dynamic panel data

\begin{abstract}
A B S T R A C T
This paper investigates serial crowdfunders' performance over successive campaigns. Adopting an expected utility maximization framework in a setting with asymmetric information about hidden entrepreneurial actions and types, we propose that crowdfunding amounts raised will follow a cyclical pattern over successive campaigns. A sample drawn from the population of serial crowdfunders on Kickstarter confirms this prediction and suggests that signaling reputations via the cyclical adjustment of campaign effort may be the mechanism driving it. Implications for theory and practice are discussed.
\end{abstract}

\section{Executive summary}

Crowdfunding, and research which studies it, has exploded in the last decade. Every year, we learn more about the different types of crowdfunders, including 'serial crowdfunders' - people who go on to launch several campaigns in succession. Nearly one-third all of funds on the leading crowdfunding platform Kickstarter are undertaken by serial crowdfunders. We still know relatively little about whether success at raising funds in one crowdfunding campaign improves serial crowdfunders' success prospects in subsequent campaigns.

Answering this research question promises to enhance our understanding of the financing of a sequence of ventures by the same entrepreneur. Prior work has explored multi-stage lending of venture capital-backed projects, and relationship lending between banks and borrowers, but analysis of the financing of multiple distinct projects by serial entrepreneurs scarce. By exploring sequences of fundraising success among serial crowdfunders, we are able to discover whether or not past success leads to future success - a question of keen interest to entrepreneurs and their backers on crowdfunding platforms.

To investigate this topic, we gather data on serial crowdfunders from the world's largest reward-based crowdfunding platform, Kickstarter. Our dataset is comprised of 29,788 serial crowdfunders who launched 75,654 campaigns since Kickstarter's inception in April 2009 and up to November 2016. In total they raised \$859 million, which represents 38.5\% of the funds raised on Kickstarter during the same period. Our analysis reveals for the first time that amounts raised by serial crowdfunders exhibit a cyclical pattern over time, with above-average funding success being followed by below-average success, which is then followed by above-average success, and so on. Our empirical investigations suggest that effort-based dynamic reputation management can explain this finding. That is, following an over-performing crowdfunding campaign, entrepreneurs can afford to supply somewhat less costly effort to the next campaign without unduly damaging their reputation with backers, resulting in underperformance; but this underperformance

\footnotetext{
* Corresponding author at: Ivey Business School, Western University, 1255 Western Rd, London, ON N6G 0N1, Canada.

E-mail addresses: ahmedkas@insper.edu.br (A. Sewaid), sparker@ivey.ca (S.C. Parker), a.kaakeh@uu.nl (A. Kaakeh).
} 
stimulates entrepreneurs to exert higher levels of effort next time to restore their reputation, leading to over-performance.

Our findings carry several implications for scholarship and practice. For example, our work highlights the importance of crowdfunders' reputations and reputation management. Thus, if an entrepreneur anticipates wanting to launch a future project about which they are especially passionate, our results recommend they exert higher effort than they might otherwise supply to that project's predecessor. This would proactively build a positive reputation which would increase the future project's chances of getting funded.

Additionally, our results suggest that serial crowdfunders may want to develop industry-specific knowledge by launching campaigns in the same industry, since changing industry seems to adversely affect their subsequent fundraising performance. We also highlight the role of timely launches of new campaigns, since waiting for longer periods of time between campaigns seems to adversely affect funding outcomes as well. Finally, our results also suggest that crowdfunding platform operators might want to provide additional guidance to crowdfunders beyond their initial campaigns. Instructions helping crowdfunders to maintain their fundraising performance in subsequent campaigns, or how to reverse unfavorable funding outcomes, could also be of considerable practical value.

\section{Introduction}

Crowdfunding has undergone tremendous growth in the last decade, with a corresponding explosion in crowdfunding research over this period (Hervé and Schwienbacher, 2018). There is growing interest in 'serial crowdfunders' who launch several crowdfunding campaigns in a sequence (Butticè et al., 2017; Kuppuswamy and Mollick, 2016; Lee and Chiravuri, 2019; Yang and Hahn, 2015). Serial crowdfunders have a disproportionate impact on aggregate fundraising, accounting for nearly one-third of all funds raised on Kickstarter, the world's leading reward-based crowdfunding (RBC) platform (Butticè et al., 2017). Prior studies on serial crowdfunders have explored their ability to build platform-specific social capital, something that novice crowdfunders lack (Butticè et al., 2017; Skirnevskiy et al., 2017). Other researchers have analyzed the role of industry factors, campaign characteristics, and serial crowdfunders' strategic responses to initial fundraising success (Butticè et al., 2018; Lin and Viswanathan, 2016; Yang and Hahn, 2015).

However, little is known about whether serial crowdfunders enjoy improved access to finance over successive campaigns. This matters for at least two reasons. First, repeated injections of finance into consecutive projects can be necessary for the creation of multiple businesses (Amaral et al., 2011; Carbonara et al., 2020; Hessels et al., 2011). Prior research studying 'traditional' sources of entrepreneurial finance (e.g. credit and equity) has had relatively little to say about funding outcomes over a sequence of ventures, no doubt reflecting an absence of comprehensive data. Even the data that does exist on the financing of a sequence of ventures tends to be limited to cases where continued financing is forthcoming (Li and Martin, 2019) - likely leading to 'success bias'. Second, evidence (including some presented in this paper) shows that serial crowdfunders receive significantly higher funding amounts, higher funding rates relative to the campaign goal, and a larger number of campaign backers, compared with non-serial crowdfunders. This makes them an especially important group to study on the grounds of value creation potential. It is therefore imperative to gain a better understanding of the drivers of serial crowdfunders' performance.

The research question investigated in this paper is: "How does serial crowdfunders' fundraising performance evolve over successive projects?" Here, as elsewhere in the crowdfunding literature, we: focus on reward-based crowdfunding (simply connoted as 'crowdfunding' hereafter); refer to crowdfunders as entrepreneurs and investors as backers; and measure fundraising performance as the amount of funds raised (Anglin et al., 2018a; Anglin et al., 2018b; Chan et al., 2019; Kuppuswamy and Bayus, 2017; Scheaf et al., 2018; Viotto da Cruz, 2018). We follow prior research in entrepreneurial finance by using the lens of expected utility maximization to analyze a setting where there is asymmetric information about hidden entrepreneurial actions (relating to entrepreneurial effort choices) and hidden entrepreneurial types (relating to different entrepreneurs' inclinations to over-bid for funds through excessive campaign goals). We distinguish between signaling by entrepreneurs to resolve moral hazard problems, and screening by backers to resolve adverse selection problems - and draw out the implications for the evolution of serial crowdfunders' fundraising performance. We go on to use web-scraped Kickstarter data to empirically estimate the nature of funding performance trajectories, and to sort between the signaling and screening mechanisms that underpin them. Our findings are striking: funding success exhibits cycles over successive campaigns, with above-average funding success being followed by below-average success, which is then followed by above-average success, and so on.

This article makes the following contributions to the crowdfunding and entrepreneurship literatures. First, we extend the crowdfunding literature by providing the first evidence on the performance of serial crowdfunders across successive campaigns. In the process, we shed light on how entrepreneurs and backers interact which enriches theory in the crowdfunding literature. Specifically, we model how both sets of agents cope with asymmetric information about entrepreneurs' effort and campaign goals; and we go on to deduce the implications of their interactions for sequences of financed projects. Second, most of the scant prior work on serial venture finance lies outside of crowdfunding and relates instead to venture capital (Gompers et al., 2009, 2010; Zhang, 2011, 2019; Nahata, 2019). We extend the theoretical analysis of serial financing to the crowdfunding setting, by considering several distinct aspects of asymmetric information within a single framework. To the best of our knowledge, our theoretical prediction of a cyclical funding pattern is a novel one in the entrepreneurial finance literature, which deserves further investigation in future work.

The rest of the paper is organized as follows. We start with a theoretical background drawing on insights from the entrepreneurial finance literature. This informs our theorizing about the fundraising performance trajectories of serial reward-based crowdfunding entrepreneurs and underlying mechanisms. We then describe the data, variables, and empirical methods used in the study. Finally, the results of our analysis are presented, and implications are discussed. 


\section{Theoretical background}

The overarching theoretical framework adopted in this paper is one of expected utility maximization. This framework is widely used in entrepreneurship research in general (Douglas and Shepherd, 2000, 2002; Kautonen et al., 2017; Parker, 1996) and entrepreneurial finance research in particular, where expected utility is usually given by the probability that an investment project succeeds multiplied by the value of the favorable outcome, less any costs of obtaining the outcome. For example, de Meza and Webb (1990) analyze the social efficiency of bank finance for risk-averse entrepreneurs who need to borrow to start a project. Entrepreneurs' expected utility is taken to be the product of the probability of project success times the utility from returns in the success state. Likewise, Keuschnigg and Nielsen $(2004,2006)$ propose a model in which entrepreneurs sell equity to investors, and whose expected utility is the product of the probability of project success and the share of returns they retain in the success state, less the costs of providing effort (where effort increases the probability of success). There are numerous other models of this type: see e.g. Parker (2018, Chaps 9, 10, and 19) for a review.

These expected utility models generally deal with problems of asymmetric information, where entrepreneurs know more about their projects and commitment to it than financiers. There are two main models of asymmetric information, one dealing with moral hazard and the other with adverse selection (de Meza and Webb, 1987; Stiglitz and Weiss, 1981). Moral hazard models arise when entrepreneurs choose how much discretionary effort to devote to a project which they request funding for. Effort is privately costly to entrepreneurs but increases their probability of success. Financiers cannot perfectly monitor entrepreneurs' effort, which is therefore partially or completely unobserved. Entrepreneurs may promise to supply high levels of effort in return for finance; but nothing can prevent them from reneging on their promise, which exposes financiers to the risk of losing their investments. Financiers therefore face a problem of asymmetric information based on hidden actions. Numerous studies have analyzed this problem in credit, equity and microfinance markets. ${ }^{1}$

Adverse selection models on the other hand relates to unobserved attributes of projects associated with different types of entrepreneurs. For example, some entrepreneurs may be intrinsically opportunistic, inflating their bids for funding above what they really need, using the surplus to finance side projects or personal consumption (Clemenz, 1986, Sec 5.3; de Meza and Gould, 1992; Bernhardt, 2000). They might also be over-optimistic (Busenitz and Barney, 1997; Manove and Padilla, 1999), causing them to over-estimate the size of the projects they can manage, inflating their loan requests at the expense of financiers' expected returns. Financiers cannot discern these deep preferences, and so face asymmetric information based on hidden types.

Entrepreneurs and financiers have developed two strategies to cope with asymmetric information problems: signaling and screening. Various signals have been discussed in the traditional finance literature, including reputations for good performance, which are built on high average levels of entrepreneurial effort. So, for example, banks are known to engage in 'relationship lending' with entrepreneurs, who want to establish a record of prompt loan repayments in return for more favorable lending terms for their venture over time (Brancati, 2015; Petersen and Rajan, 1994; Uchida et al., 2012). Reputations also play a prominent role in venture capital markets (Amit et al., 1998; Atanasov et al., 2012; Kaplan, 2003) and trade credit (McMillan and Woodruff, 1999). Entrepreneurs may value those reputations for their own sake (e.g. because they support their social identity: Berzonsky, 1994) as well as for being a means of obtaining resources.

Screening on the other hand refers to information-gathering efforts by financiers intended to uncover hidden information about heterogeneous entrepreneurial types, thereby enabling more profitable investments to be made (Drover et al., 2017; Kaplan and Strömberg, 2001). For example, consider the case where financiers anticipate that some entrepreneurs are 'over-bidder' types who are liable to request more funds than they actually need to support their project, so they can spend the surplus on side projects or personal consumption. Suppose one type of entrepreneur does not over-bid for funds while the other type does. Financiers do not know what type a given individual entrepreneur is, because their preferences are not observable; but they want to screen out the ones who tend to over-bid. The amount of funds that an entrepreneur requests can serve as a noisy indicator of their type - noisy, because even after taking account of observable factors relating to an entrepreneur's application for funding (e.g. industry sector, product type, etc.), financiers cannot be entirely sure that high bid amounts are unjustified. Conditional on observable characteristics, persistent and excessive funding requests are likely to reduce the probability that financiers choose to finance certain entrepreneurs, whom they screen out as 'bad risks'.

To summarize, expected utility maximization by borrowers who request financing is the dominant conceptual paradigm in the traditional entrepreneurial finance literature. This literature illuminates various facets of the process by which entrepreneurs raise finance from imperfectly informed financiers. Prior research on this tradition focuses on two distinct settings, each with an associated choice variable. One class of models focuses on the private effort entrepreneurs choose to increase the payoff of their project if successful, and which they want to signal to separate themselves from less hard-working types. A second class of model explores how financiers screen entrepreneurs based on observable information (such as prior funding requests) when all entrepreneurs desire high levels of funding, but some entrepreneurial types are more prone to over-bid than others.

Before proceeding, we acknowledge that numerous other factors might influence entrepreneurial decision-making, especially in uncertain early-stage endeavors like crowdfunding, which may not fit easily within the traditional expected utility maximization framework. As noted earlier, for example, early-stage entrepreneurs might be over-optimistic when uncertainty is rife, or value factors

\footnotetext{
${ }^{1}$ For credit market studies, see e.g. Stiglitz and Weiss (1981), de Meza and Webb (1987), Williamson (1987) and Ghatak et al. (2001). For equity markets, see Keuschnigg and Nielsen (2004, 2006), Schmidt (2003) and Ellingsen and Kristiansen (2011). For a microfinance study, see Ghatak and Guinnane (1999).
} 
other than financial returns. It turns out that the expected utility maximization framework can be extended to handle over-optimism by replacing objective with subjective probabilities, as we go on to show in the appendix; also, additional non-financial factors like prosocial motivations can be added to the utility function without changing the theoretical predictions. To some extent, empirical tests of the hypotheses generated in the next section also test the underlying assumptions of the usefulness of the expected utility paradigm; and, in addition, our empirical analysis will control for time-varying factors that are not explicitly present in the model, while 'differencing away' other time-invariant factors as well.

\section{Theory development}

The literature discussed above refers to 'conventional' sources of finance, such as debt and equity. Our contention in what follows is that the asymmetric information problems and resolution mechanisms at play in those models also apply to the crowdfunding setting. In this setting, backers play the role of financiers who face asymmetric information about projects that entrepreneurs pitch on a crowdfunding platform; and like conventional investors, backers observe the amounts of funds previously raised and the amounts of funds currently being requested (Li and Martin, 2019). The conceptual analysis that follows uses the same expected utility framework as above and adapts to the crowdfunding context the effort-based signaling and funding goal-based screening mechanisms discussed earlier. In what follows we provide a non-technical exposition in the main body of the text, establishing and providing intuition for our propositions while relegating mathematical underpinnings and proofs to an online appendix.

The basic set-up is this. Entrepreneurs gain utility from the funds they raise during the campaign. When launching a crowdfunding campaign, entrepreneurs know that they might not attract enough funding to hit their funding target, which they set at the start of the campaign. However, entrepreneurs can take actions which affect the probability of funding and the amount raised if they are funded. Expected utility at time $t$ is given by the product of utility from the funds raised and the probability of being funded in the current campaign - less any utility lost by taking costly actions. The main variable of interest is 'funding success', i.e. the amount of funds raised, since that directly generates entrepreneur utility.

Following the broad structure of the general entrepreneurial finance literature, the remainder of this section is divided into two parts. The first discusses how serial crowdfunders (hereafter simply 'entrepreneurs') choose effort to signal reputation and elicit finance from backers under conditions of asymmetric information about hidden actions. The second discusses how backers use information about declared campaign goals, i.e. requested funds, to screen serial entrepreneurs under conditions of asymmetric information about hidden types.

\subsection{Signaling hidden effort via reputation}

The empirical crowdfunding literature has identified several determinants of fundraising performance based on the quality of pitches and the attractiveness of project pages (Allison et al., 2017; Lagazio and Querci, 2018; Mollick, 2014) High quality campaigns require sustained effort to produce, so there is a positive association between pre-campaign effort and ultimate campaign funding success. As in conventional finance models, effort is privately costly for entrepreneurs to supply (Chemla and Hennessy, 2014; Watson, 1984), and a moral hazard problem arises since entrepreneurs have an incentive to shirk or direct their effort to a side project (Fairchild, 2011). In a simple one-shot project setting, entrepreneurs would choose effort to balance expected costs and returns for that project alone (Parker, 2014); but in a dynamic serial crowdfunding setting there is an additional consideration, since a sequence of effort choices can enable an entrepreneur to build - or lose - a reputation (Mailath and Samuelson, 2001; Wernerfelt, 1988). Thus, following standard moral hazard finance models, while backers cannot observe entrepreneurs' effort directly, they can observe the funding amounts previously raised by entrepreneurs. This information is useful because amounts raised are positively related to effort (Schwienbacher, 2018). Backers then condition their decisions on whether to support a campaign on prior finding success, which therefore affects the probability a project is funded.

The notion that third parties (like backers) assign reputation based on recent performance finds numerous parallels in real life, including in popular culture. Famously, the silent movie star Douglas Fairbanks Jr. once observed that 'man is only as good as his last picture'. This sentiment has since been applied to many diverse settings outside of the world of acting. In the case of crowdfunding, backers can also be expected to reward entrepreneurs based on their 'last picture', i.e. the amount they raised in their previous campaign. For their part, entrepreneurs look forward to the reputation they will enjoy once their campaign completes, which depends on both their 'last picture' (i.e. the sum raised in their last campaign) and the amount they raise in the current campaign. ${ }^{2}$

Combining in this way reputation signals based on dynamic effort when effort is costly generates an interesting and possibly unexpected prediction: both optimal effort and therefore funding success are likely to follow a cyclical temporal pattern, whereby above-average funding success is followed by below-average success, which is then followed by above-average success, and so on. To grasp the intuition for this prediction, consider first what would happen if the cost of effort was zero. Then, maximal effort would always be optimal: entrepreneurs would always exert high effort and enjoy good reputations. There would effectively be no moral hazard problem. But when effort is privately costly and cannot be credibly communicated to backers, serial crowdfunding entrepreneurs face a trade-off between on the one hand incurring costs of effort to maintain or enhance their reputation, and on the other

\footnotetext{
${ }^{2}$ Of course, reputation is multidimensional and could also incorporate information about e.g. whether the entrepreneur fulfilled their promises after the campaign, social media profiles, etc. Even taking account of this information, the moral hazard issue remains, which is why signaling through amounts raised remains of interest. See the discussion section for more on reputations in crowdfunding.
} 
hand economizing on effort while coasting on the reputation they have established to date. If an entrepreneur currently has a relatively bad reputation, they will face a strong incentive to restore it by exerting higher levels of effort for the next campaign; whereas if they currently have a good reputation, they can afford to coast on it for a while and economize on costs (Mailath and Samuelson, 2001). This is what imparts cyclicality into effort and hence funding success (which is directly related to effort).

This result is summarized in the following proposition. Section A.1 of the online appendix provides a formal proof, derived from a simple expected utility model which incorporates the mechanisms described above.

Proposition 1. (Reputation Mechanism) Both campaign effort and funding success of serial crowdfunders are cyclical over successive campaigns. ${ }^{3}$

\subsection{Screening based on observable funding goal information}

A different mechanism, based on screening, can also generate cycles in funding success. As in the signaling model, entrepreneurs maximize their expected utility while backers condition their decisions of whether to support projects on observable signals about current and previous campaigns. We abstract from effort considerations to focus attention on an adverse selection problem with hidden types.

If all entrepreneurial types were the same, there would be no asymmetric information problem and no need for screening. However, in the serial crowdfunding setting, backers know that entrepreneurial types are heterogeneous and that these types are hidden. Specifically, entrepreneurs are heterogeneous in terms of their tendency to bid only for the funds they need to execute their project, or to over-bid. That is, some hidden entrepreneur types regularly set funding goals which exceed what they need, to finance side projects or personal consumption which do not add any value to the backers, while other types choose funding goals which just cover what they need. Hence, backers may face a problem of adverse selection.

All else equal, backers want to finance those entrepreneurs who do not over-bid; but given asymmetric information they struggle to distinguish one type from another. Backers know that some projects are more capital-intensive than others, and that some product offerings and business models require more financial input than others. Backers can also observe details about serial crowdfunders' prior projects and assess those capital needs as well. However, although backers have access to this information, they need to find a way to screen out the undesirable types. We propose that backers can screen entrepreneurs by conditioning their likelihood of giving funds on the entrepreneur's current and most recent funding requests.

Previous project funding goals are a useful input into backers' screening process because, all else equal, a systematic tendency for an entrepreneur to overbid would likely be reflected in a sequence of high funding goals. Backers can use this information to detect and screen out over-bidders. Their probability of funding a current project will therefore be a decreasing function of the size of both the current project goal and the previous project goal.

Entrepreneurs therefore face a tradeoff in setting a higher project goal: on one hand, a higher goal is associated with higher funding amounts if the project is funded; but on the other hand, it decreases the probability that the project will be fully funded (Anglin et al., 2018a; Anglin et al., 2018b; Butticè et al., 2017; Mollick, 2014). Anticipating that they are being screened based on their funding requests, entrepreneurs make their current goal choice in light of their prior campaign goal. Following a campaign with a high goal, entrepreneurs are restrained from setting a high goal for their current project for fear of being screened adversely by backers as overbidding types. Hence, they would do better by moderating their goals and asking for a lower amount this time. Likewise, if they set a low goal last time, entrepreneurs would face less of a hit to their funding probability by setting a higher goal this time. Consequently, funding goals will exhibit cyclicality, as will funding success, since success varies directly with funding goals. This result, which is proven in section A. 3 of the online appendix, is summarized in the following proposition:

Proposition 2. (Screening based on Project Goals) Both funding goals and funding success of serial crowdfunders are cyclical over successive campaigns.

\section{Data and methods}

\subsection{Data}

Kickstarter is the world's leading reward-based crowdfunding platform and has served as the main source of data for research on

\footnotetext{
${ }^{3}$ What if entrepreneurs are over-optimistic? Section A.2 of the online appendix shows that moderate over-optimism weakens the degree of cyclicality predicted by Proposition 1 but does not overturn it unless the degree of over-optimism is sufficiently high. The intuition is that, compared with realists, over-optimists over-estimate the probability of funding success, which provides a positive incentive to exert greater effort (see also Gervais and Goldstein, 2007; Landier and Thesmar, 2009; Parker, 2009; Puri and Robinson, 2007). Greater effort then increases the expected returns to high effort for the next project since backers are more likely to fund projects where high effort has been provided in the previous one. Sufficiently high levels of over-optimism can therefore induce positive serial correlation in funding success and effort, in contrast to the cyclicality prediction of Proposition 1. What are the empirical implications? Suppose Proposition 1 receives empirical support. In that case, without knowing crowdfunders' idiosyncratic optimism, one can only infer that to the extent over-optimism exists among entrepreneurs, it must be relatively modest in nature, in the sense that it does not overwhelm cyclicality arising from reputation-building. Appendix A.2 pins down the offsetting effects precisely in terms of the expected utility model.
} 
crowdfunding in general (Agrawal et al., 2015; Mollick, 2014), and serial crowdfunders in particular (Butticè et al., 2017, 2018; Skirnevskiy et al., 2017; Yang and Hahn, 2015). Similar to previous literature, we proceed by extracting campaign-specific and entrepreneur-specific data from Kickstarter and build an initial dataset which is comprised of all projects launched on Kickstarter since its inception in April 2009 up to November 2016. Our initial dataset consists of a total of 294,500 projects launched by 248,634 entrepreneurs, successfully raising $\$ 2.24$ billion.

Butticè et al. (2017) coined the term "serial crowdfunder" which they defined as an entrepreneur who launches more than one project on the same crowdfunding platform. 75,654 projects in our initial dataset were launched by 29,788 serial crowdfunders. This represents $11.94 \%$ of the founders on Kickstarter. Yet although serial crowdfunders are relatively rare, they account for a disproportionate share (38.5\%, $\$ 859$ million) of all the funds raised on Kickstarter during the same period. To investigate the performance of serial crowdfunders over their successive ventures, we need a minimum of three observations per serial crowdfunder. ${ }^{4}$ This limits our observations to 31,422 projects launched by 7672 serial crowdfunders. Information about the distribution of campaigns in our sample appears in Table 1. Given that omitting serial crowdfunders with only two projects from our sample, for purely econometric reasons, might cause selection bias (specifically if serial crowdfunders with two projects differ from those with three or more projects), we: 1) deploy the Arellano and Bond (1991) dynamic panel data estimator which has been shown not to suffer from selection bias (Al-Sadoon et al., 2019), and 2) conduct a major set of robustness checks in Section 5.2 to examine this issue further.

\subsection{Measures}

\subsubsection{Dependent variable}

Different crowdfunding platforms utilize different funding mechanisms, the main ones being 'Keep-it-all' and 'All-or-nothing' mechanisms (Cumming et al., 2014). In a Keep-it-all mechanism, the entrepreneur gets to keep all amounts pledged by backers regardless of whether the campaign goal is met or not. In an All-or-nothing mechanism, in contrast, the campaign goal needs to be achieved before any funds are disbursed to the entrepreneur. Kickstarter only offers an All-or-nothing mechanism. This has led some scholars to measure campaign success as a binary variable recording whether or not the entrepreneur achieved their campaign goal (Butticè et al., 2017; Colombo et al., 2015; Courtney et al., 2017). However, researchers interested in gauging campaign performance have utilized continuous measures of crowdfunding outcomes such as the amount of capital committed by backers to a specific project (Anglin et al., 2018b; Chan et al., 2019; Kuppuswamy and Bayus, 2017; Scheaf et al., 2018; Viotto da Cruz, 2018).

In a similar vein, our interest in this study is to investigate performance over successive campaigns. Thus, to gauge fundraising performance, $\Pi_{i, T}$ for $i$ 's campaign $T$, we operationalize fundraising performance as a continuous variable, Amount Raised, measuring the amount of capital committed by backers to the campaign (Anglin et al., 2018a; Anglin et al., 2018b). This continuous measure is richer and contains more information than simply whether the project was funded, given the continuum of possible funding outcomes. Underfunded project amounts are included in Amount Raised, even though no funds are disbursed to crowdfunders, since campaigns able to secure more in commitments from backers are considered to have performed better than those attracting little funding. The same holds for campaigns meeting their goals. Amount Raised is expressed in US dollars; for campaigns not denominated in US dollars, we convert the amount raised into US dollars by using Kickstarter's effective exchange rate for that specific campaign (Skirnevskiy et al., 2017). Due to the skewness of this variable and the zero values encountered, we transform it using the inverse hyperbolic sine transformation which has a similar interpretation to that of the natural log (Anglin et al., 2018a; Burbidge et al., 1988; Franke and Richey, 2010; Sauerwald et al., 2016). ${ }^{5}$

\subsubsection{Independent variables}

Our conceptual discussion identified two constructs which need empirical counterparts: crowdfunder effort and their campaign goal. First, we measure effort as the number of days spent by the entrepreneur since campaign creation on Kickstarter up to the day the campaign goes public (Kunz et al., 2017; Zhang et al., 2017). We contend that this captures the time spent by the entrepreneur preparing the campaign since the entrepreneur (not the platform) decides when to launch the campaign. ${ }^{6}$ This measure, which is similar to the business gestation period in the traditional business launching setting (Alsos and Kolvereid, 1998), gives rise to the variable Preparation Time. We utilize this measure to investigate whether effort follows a cyclical trajectory over time (Proposition 1 ).

Second, prior to the launch of a campaign, an entrepreneur decides on the amount of capital requested for the launch of his or her project. We use the entrepreneur's declared goal, a variable denoted Project Goal, to investigate whether capital requested follows a cyclical trajectory over time (Proposition 2).

\subsubsection{Control variables}

Our study controls for several variables which have been shown in prior research to significantly correlate with campaign performance. These include a) campaign-specific factors chosen by the entrepreneur before campaign launch; b) factors affecting ultimate

\footnotetext{
${ }^{4}$ This will be explained in more detail in Section 4.3 which presents the econometric methods used in our analysis.

5 The inverse hyperbolic sine transformation is computed as follows: $\sinh ^{-1}(y)=\log \left(y+\left(y^{2}+1\right)^{1 / 2}\right)$.

${ }^{6}$ From that date there is a minor $30 \mathrm{~h}$ delay, on average, required by Kickstarter to review the project. See Benovic, C. (2016). The Project Review Process: From Submitting to Getting Approved. Retrieved from https://www.kickstarter.com/blog/everything-you-need-to-know-about-the-projectreview-process. We note that there might be concerns that Preparation Time truly measures effort: see Section 5.2 below, which conducts several robustness checks to explore this issue in detail.
} 
Table 1

Serial crowdfunders' activity.

\begin{tabular}{|c|c|c|c|c|}
\hline Number of Projects & Number of Crowdfunders & Total Number of Campaigns & Amounts Pledged & Successfully Raised \\
\hline 3 & 4570 & 13,710 & $\$ 215,662,392$ & $\$ 199,304,357$ \\
\hline 4 & 1498 & 5992 & $\$ 96,014,635$ & $\$ 88,931,823$ \\
\hline 5 & 652 & 3260 & $\$ 39,282,601$ & $\$ 36,113,045$ \\
\hline 6 & 370 & 2220 & $\$ 49,031,515$ & $\$ 46,200,981$ \\
\hline$>6$ & 582 & 6240 & $\$ 148,837,772$ & $\$ 137,411,022$ \\
\hline Total & 7672 & 31,422 & $\$ 548,828,915$ & $\$ 507,961,228$ \\
\hline
\end{tabular}

campaign performance at and just after launch; and c) factors related to previous crowdfunding endeavors.

For a), backers in reward-based crowdfunding settings support projects in return for promised rewards. Entrepreneurs usually offer different rewards, at different prices, for backers to choose from. The literature has shown that the number of rewards offered significantly affects campaign outcomes. Therefore, we control for the number of rewards offered by the entrepreneur, Rewards (Du et al., 2018; Zhang and Chen, 2019). Research has also shown that campaign content might significantly affect campaign performance (Mollick, 2014). To capture this, controls for visual and textual variables were included in the model, namely the presence of a Video Pitch (a dummy variable $=1$, if campaign has a video pitch); the number of videos included (Video Count); the number of images attached (Image Count); and the Text Length (in thousands of words) of the campaign content section (Courtney et al., 2017; Davis et al., 2017; Parhankangas and Renko, 2017). The Duration of the campaign is controlled for, too. Finally, projects launched in the US tend to enjoy better campaign outcomes: the dummy variable US is included to capture this effect (Butticè et al., 2017; Mollick, 2014).

Turning to b), upon launch two important factors play a crucial role in the campaign outcome, Staff Pick and Quick Update. Staff Pick is whether the campaign is featured by Kickstarter staff (a dummy variable $=1$ if campaign was featured). This can be construed as a signal of campaign quality. Quick Update measures whether the entrepreneur was quick to update backers on campaign progress (a dummy variable $=1$ if entrepreneur updates backers within the first three days of the campaign) - as recommended by Kickstarter (Mollick, 2014; Skirnevskiy et al., 2017).

For c), since our study focuses on serial entrepreneurs in the crowdfunding setting, we control for factors related to previous crowdfunding endeavors. Butticè et al. (2017) highlighted the effect of platform-specific social capital on campaign performance. Given the nature of social relationships in an online setting, we follow Butticè et al. (2017) by using as a proxy for social capital the number of comments accumulated by the crowdfunder over previous crowdfunding campaigns (Social Capital). To control for industryspecific human capital, we check whether the current campaign is launched in the same industry as that of the previous campaign. Kickstarter has 15 industry categories, and we define a dummy variable Industry Change to take the value 1 if the current campaign is launched in an industry different to that of the prior campaign, and 0 otherwise. This is consistent with the literatures on serial entrepreneurship and crowdfunding (Parker, 2013; Eggers and Song, 2015; Lee and Chiravuri, 2019). Similar to Butticè et al. (2017), we also control for the time elapsed (in days) since the last immediate campaign (Time Since Last Project). To control for re-runs of a previous campaign, we construct the variable Project Similarity which measures the percentage of textual similarity between the current project description and the prior campaign's project description.

In addition to these control variables, we followed Anglin et al. (2018a) by including a full set of dummy variables to capture industry categories as well as a full set of year effects (2009-2016). Given the skewness of our continuous variables (dependent and independent) and the zero values encountered, we transformed all the continuous variables using the inverse hyperbolic sine transformation. Table 2 presents a list of all the variables used in our analysis together with their descriptions.

\subsection{Methods}

We estimate the following dynamic panel data (DPD) regression model to determine the performance trajectory of the dependent variable:

$$
\Pi_{i, \mathrm{~T}}=\alpha_{i}+\gamma \Pi_{i, \mathrm{~T}-1}+\beta \mathrm{X}_{i, \mathrm{~T}}+v_{i}, \mathrm{~T}
$$

Here, the subscript $i$ denotes the serial crowdfunder and $\mathrm{T}$ denotes the campaign number. $\alpha_{i}$ is an individual-specific fixed effect capturing serial crowdfunder $i$ 's long run performance. Controlling for these individual fixed effects helps us draw proper inferences about the performance characteristics of the population of serial crowdfunders (Hsiao, 2014). $\Pi_{i, \mathrm{~T}}$ denotes the amount of capital raised by serial crowdfunder $i$ for campaign T. The coefficient $\gamma$ expresses the trajectory of the dependent variable under investigation $(\gamma>1$ : increasing trajectory; $0<\gamma<1$ : depreciating trajectory converging towards $\alpha_{i} ; \gamma=0$ : flat trajectory; $-1<\gamma<0$ : cycling trajectory around $\alpha_{i}$ ). $\mathrm{X}_{i, \mathrm{~T}}$ denotes time varying variables that will be included in the model, and $v_{i \mathrm{~T}}$ denotes a random error term.

Since our analysis investigates the effect of lagged performance on current performance, there is a correlation between the lagged dependent variable and the error term. This violates the exogeneity assumption, invalidating the use of static fixed effects models in such situations (Wooldridge, 2005). Indeed, Nickell (1981) shows that using dynamic OLS fixed effects estimators would bias the coefficient on the lagged dependent variable downwards, while the random effects specification would bias the coefficient on the lagged dependent variable upwards. To circumvent this issue we use Arellano and Bond's (1991) dynamic panel data estimator. Arellano and Bond (1991) proposed the generalized method of moments estimator, taking the first difference of both sides of (1) to eliminate individual-specific fixed effects. This differencing process implies that only campaign-varying variables can be included in 
Table 2

Variables description.

\begin{tabular}{ll}
\hline Variable & Description \\
\hline Amount Raised & The amount of capital raised during the campaign in US dollars. \\
Project Goal & The campaign's goal in US dollars. \\
Preparation Time & Number of days spent by the entrepreneur preparing the campaign before launch. \\
Social Capital & Number of accumulated comments over previous campaigns. \\
Industry Change & A dummy variable $=1$, if current campaign industry is different from the previous campaign. \\
Time Since Last Project & Time elapsed since the last project completion in days. \\
Project Similarity & Percentage of textual similarity between current and previous campaign's project description. \\
Rewards & Number of rewards offered by the entrepreneur in the campaign. \\
Video Pitch & A dummy variable $=1$, if campaign has a video pitch. \\
Video Count & Number of Videos in campaign's content section. \\
Image Count & Number of images in campaign's content section. \\
Text Length & Text length of campaign's content section in thousands. \\
Duration & Total campaign duration in days. \\
Staff Pick & A dummy variable $=1$, if campaign was featured. \\
Quick Update & A dummy variable $=1$, if there was an update in the first three days of the campaign. \\
US Dummy & A dummy variable $=1$, if campaign was launched in the US. \\
Industry Controls & Industry dummies proxied by Kickstarter's 15 categories. \\
Time dummies & Time dummies for years 2009-2016. \\
\hline
\end{tabular}

All continuous variables were transformed using the inverse hyperbolic sine transformation due to the variables' skewness and zero values encountered. The inverse hyperbolic sine transformation has similar intrepretation to that of log transformed variables.

the model, and that we can only analyze entrepreneurs who launched three or more projects. However, it is a price worth paying for two main reasons. First, this technique corrects for the biased coefficient estimates of ordinary least squares and static fixed effects models, yielding more reliable and consistent coefficients (Flannery and Hankins, 2013). Second, in principle it overcomes potential sample selection biases that static fixed effects models are vulnerable to, which allows us to draw proper inferences for the population of serial crowdfunders (see Al-Sadoon et al., 2019, and Hsiao, 2014, for details).

\subsection{Descriptive statistics}

Table 3 displays the descriptive statistics for the groups of novice and serial crowdfunders in our initial dataset as well as the significance of differences between them using two tailed $t$-tests. The unit of analysis (in Table 3 only) is the entrepreneur: in this table we average over project characteristics for each entrepreneur. The left-hand panel of Table 3 shows that on average serial crowdfunders receive significantly higher funding amounts, higher funding percentages relative to the campaign goal (Funding Ratio), and a larger number of campaign backers (Backers), compared with non-serial crowdfunders. Moreover, serial crowdfunders have more dynamic campaigns in the sense that, on average, their campaigns receive more comments by backers as well as more updates by the entrepreneur. There is however no significant difference in serial and novice crowdfunders' project goals. The significant difference in the performance of serial crowdfunders, in comparison to novice crowdfunders, confirms the need to investigate their performance separately.

The right-hand panel of Table 3 compares serial crowdfunders having only two projects (whom we eliminate from our regression analysis below for purely econometric reasons), with serial crowdfunders having three or more projects. In terms of performance, we detect no significant differences in either the average amount raised or the number of campaign backers. However, we observe

Table 3

Mean differences between different types of crowdfunders.

\begin{tabular}{|c|c|c|c|c|c|c|}
\hline & \multicolumn{3}{|c|}{ Non-Serial vs Serial } & \multicolumn{3}{|c|}{ Serial with 2 projects vs Serial with $3+$ projects } \\
\hline & Non-Serial & Serial & Two tailed t-test & Serial (2 Projects) & Serial (3+ Projects) & Two tailed t-test \\
\hline Amount Raised (in $\$ 000 \mathrm{~s}$ ) & 7.22 & 9.35 & $* * *$ & 9.31 & 9.49 & \\
\hline Funding Ratio (\%) & $118 \%$ & $420 \%$ & $* * *$ & $264 \%$ & $872 \%$ & $* * *$ \\
\hline Backers & 83.35 & 112.56 & $* * *$ & 112.90 & 111.58 & \\
\hline Comments & 19.71 & 32.05 & $* * *$ & 26.79 & 47.22 & $* * *$ \\
\hline Updates & 3.75 & 4.99 & $* * *$ & 5.39 & 3.82 & $* * *$ \\
\hline Project Goal (in $\$ 000 \mathrm{~s}$ ) & 44.00 & 39.00 & & 46.00 & 19.00 & $* *$ \\
\hline Video Pitch & $71 \%$ & $65 \%$ & $* * *$ & $73 \%$ & $41 \%$ & $* * *$ \\
\hline Video Count & 0.22 & 0.25 & $* * *$ & 0.28 & 0.19 & $* * *$ \\
\hline Image Count & 4.18 & 5.02 & $* * *$ & 5.29 & 4.25 & $* * *$ \\
\hline Word Count (in thousands) & 2.44 & 2.36 & $* * *$ & 2.62 & 1.59 & $* * *$ \\
\hline Duration (in days) & 34.78 & 30.52 & $* * *$ & 34.68 & 18.54 & $* * *$ \\
\hline \# of Entrepreneurs & 218,846 & 29,788 & & 22,116 & 7672 & \\
\hline
\end{tabular}

\footnotetext{
* p-value $<0.10$.

**value $<0.05$.

p-value $<0.01$.
} 
Table 4

Descriptive statistics, correlation matrix, \& VIFs.

\begin{tabular}{|c|c|c|c|c|c|c|c|c|c|c|c|c|c|c|c|c|c|c|c|c|}
\hline Variable & Mean & SD & 1 & 2 & 3 & 4 & 5 & 6 & 7 & & 8 & 9 & 10 & 11 & 12 & 13 & 14 & 15 & 16 & VIF \\
\hline $\begin{array}{l}\text { Amount Raised (in } \$ 000 \\
\text { s) }\end{array}$ & 17.31 & 180.13 & 1.00 & & & & & & & & & & & & & & & & & DV \\
\hline 2 Project Goal (in $\$ 000 \mathrm{~s}$ ) & 30.46 & 870.30 & $0.15^{* * *}$ & $1.00 * * *$ & & & & & & & & & & & & & & & & 1.25 \\
\hline $3 \begin{array}{l}\text { Preparation Time (in } \\
\text { days) }\end{array}$ & 36.85 & 93.90 & $0.30 * * *$ & $0.22 * * *$ & 1.00 & & & & & & & & & & & & & & & 1.31 \\
\hline 4 Social Capital & 533.17 & 8225.84 & $0.41 * * *$ & $0.04 * * *$ & $* 0.17 * * *$ & 1.00 & & & & & & & & & & & & & & 1.96 \\
\hline 5 Industry Change & 0.18 & 0.38 & $-0.12^{* * *}$ & $-0.07 * * *$ & $-0.02 * * *$ & $0.05 * * *$ & 1.00 & & & & & & & & & & & & & 1.09 \\
\hline $6 \begin{array}{l}\text { Time Since Last Project } \\
\text { (in days) }\end{array}$ & 171.04 & 240.64 & $0.15 * * *$ & $-0.08 * k *$ & 0.08 & $0.46^{* * *}$ & $0.29 * * *$ & 1.00 & & & & & & & & & & & & 1.37 \\
\hline 7 Project Similarity & 0.17 & 0.26 & $0.04^{* * *}$ & $-0.08 * * *$ & $-0.11 * * *$ & $0.20 * * *$ & -0.00 & $0.41 * * *$ & 1.00 & & & & & & & & & & & 1.17 \\
\hline 8 Rewards & 9.24 & 6.77 & $0.44^{* * *}$ & $0.18 * * *$ & $0.23 * * *$ & $0.18 * * *$ & $-0.06 * * *$ & $0.09 * *$ & 0.02 & $* * * 1.00$ & & & & & & & & & & 1.31 \\
\hline 9 Video Pitch & 0.73 & 0.45 & $0.35 * * *$ & $0.17 * * *$ & $0.23 * * *$ & $0.11 * * *$ & $-0.06 * * *$ & $0.07 * * *$ & 0.02 & $* * * 0.29$ & $9 * * * 1.00$ & & & & & & & & & 1.18 \\
\hline 10 Video Count & 0.34 & 1.12 & $0.21 * * *$ & $0.14 * * *$ & $0.15 * * *$ & $0.17 * * *$ & $-0.04 * * *$ & $0.06 * * *$ & 0.03 & $* * * 0.15$ & $5 * * * 0.14$ & $4 * * *$ & 1.00 & & & & & & & 1.13 \\
\hline 11 Image Count & 8.03 & 12.30 & $0.43^{* * * *}$ & $0.17 * * *$ & $0.33 * * *$ & $0.41 * * *$ & 0.00 & $0.16^{* * * *}$ & 0.07 & $* * * 0.36$ & $6 * * * 0.21$ & $1 * * *$ & $0.27^{* * * *}$ & 1.00 & & & & & & 1.81 \\
\hline 12 Text Length (in $000 \mathrm{~s}$ ) & 2.92 & 3.09 & $0.39 * * *$ & $0.24 * * *$ & $0.25 * * *$ & $0.21 * * *$ & $-0.05 * * *$ & $0.06 * * *$ & 0.03 & $* * * 0.36$ & $6 * * * 0.25$ & $5 * * *$ & $0.24^{* * *}$ & $0.49^{* * *}$ & 1.00 & & & & & 1.48 \\
\hline 13 Duration (in days) & 33.23 & 14.03 & $-0.01 * * *$ & $0.26 * * *$ & $0.04 * * *$ & $-0.11 * * *$ & $-0.02 * * *$ & $-0.08 * * *$ & -0.07 & $* * * 0.06$ & $6 * * * 0.04$ & $4 * * *$ & 0.00 & $-0.03 * * *$ & $0.04 * * *$ & 1.00 & & & & 1.11 \\
\hline 14 Staff Pick & 0.14 & 0.34 & $0.33 * * *$ & $0.12 * * *$ & $0.12 * * *$ & 0.18 **** & $-0.02 * * *$ & $0.08 * * *$ & -0.01 & ** 0.19 & $9 * * * 0.17$ & $7^{* * *}$ & $0.09 * * *$ & $0.19 * * *$ & $0.19^{* * *}$ & 0.00 & 1.00 & & & 1.15 \\
\hline 15 Quick Update & 0.29 & 0.45 & $0.30 * * *$ & $0.03 * * *$ & $0.10 * * *$ & $0.18 * * *$ & $-0.01 * * *$ & $0.07 * * *$ & -0.01 & $* * * 0.19$ & $9 * * * 0.14$ & $4^{* * *}$ & $0.13 * * *$ & $0.15 * * *$ & $0.16^{* * * *}$ & 0.01 & $0.14 * * *$ & 1.00 & & 1.11 \\
\hline 16 US & 0.84 & 0.37 & $0.04 * * *$ & $-0.02 * * *$ & $0.02 * * *$ & 0.00 & 0.00 & $0.04 * * *$ & 0.00 & 0.05 & $5 * * * 0.07$ & $7^{* * *}$ & $-0.01 * * *$ & $-0.10 * * *$ & $-0.03 * * *$ & 0.00 & 0.00 & $0.04 * * *$ & 1.00 & 1.03 \\
\hline
\end{tabular}

* p-value $<0.10$.

p-value $<0.05$.

p-value $<0.01$ 
Table 5

Dynamic panel data model: performance trajectory of serial crowdfunders.

\begin{tabular}{|c|c|c|c|c|c|c|c|c|c|c|}
\hline \multirow[b]{3}{*}{ Amount Raised $\mathrm{T}_{-1}$} & \multicolumn{10}{|c|}{ Dependent Variable: Amount Raised ${ }_{\mathrm{T}}$} \\
\hline & \multicolumn{2}{|c|}{ I } & \multicolumn{2}{|c|}{ II } & \multicolumn{2}{|c|}{ III } & \multicolumn{2}{|c|}{ IV } & \multicolumn{2}{|c|}{$\mathrm{V}$} \\
\hline & $0.1933^{* * *}$ & $(0.0077)$ & $-0.1813^{* * *}$ & $(0.0098)$ & 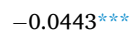 & $(0.0022)$ & $-0.0662^{* * * k}$ & $(0.0040)$ & $-0.0917^{\text {**** }}$ & $(0.0033)$ \\
\hline Social Capital & $0.3306^{* * *}$ & $(0.0119)$ & 0.0092 & $(0.0226)$ & & & & & $-0.2333^{* * *}$ & $(0.0146)$ \\
\hline Industry Change & $-0.2845^{* * *}$ & $(0.0410)$ & $-0.2096^{* * *}$ & $(0.0489)$ & & & & & $-0.1837^{* * *}$ & $(0.0317)$ \\
\hline Time Since Last Project & $0.1362^{* * *}$ & $(0.0133)$ & $0.0768^{* * *}$ & $(0.0158)$ & & & & & $-0.0542^{* \cdots *}$ & $(0.0101)$ \\
\hline Project Similarity & $0.2814^{* * *}$ & $(0.0748)$ & $0.2981^{* * *}$ & $(0.0892)$ & & & & & $0.3454^{* * *}$ & $(0.0463)$ \\
\hline Project Goal & $0.1109^{* * *}$ & $(0.0111)$ & $0.1327^{* \ldots *}$ & $(0.0147)$ & & & $0.1030^{* * *}$ & $(0.0111)$ & $0.1000^{* * *}$ & $(0.0102)$ \\
\hline Rewards & $0.6816^{\text {*** }}$ & $(0.0287)$ & $0.5354^{* \ldots *}$ & $(0.0360)$ & & & $0.5796^{* * *}$ & $(0.0225)$ & $0.5634^{* * * *}$ & $(0.0205)$ \\
\hline Video Pitch & $0.5496^{* * *}$ & $(0.0420)$ & $0.3066^{* * *}$ & $(0.0526)$ & & & $0.4916^{* * *}$ & $(0.0356)$ & $0.4645^{* * *}$ & $(0.0352)$ \\
\hline Video Count & $0.1270^{* * *}$ & $(0.0318)$ & $0.1841^{* * *}$ & $(0.0377)$ & & & $0.1510^{* * *}$ & $(0.0167)$ & $0.1194^{* * *}$ & $(0.0162)$ \\
\hline Image Count & $0.1786^{* * *}$ & $(0.0165)$ & $0.1555^{* * *}$ & $(0.0212)$ & & & $0.1400^{* * *}$ & $(0.0088)$ & $0.1424^{* * * *}$ & $(0.0087)$ \\
\hline Text Length & $0.1814^{* * *}$ & $(0.0259)$ & $0.0944 * * *$ & $(0.0329)$ & & & $0.1341^{* * *}$ & $(0.0169)$ & $0.1101^{* * * *}$ & $(0.0158)$ \\
\hline Duration & $0.1750^{* * *}$ & $(0.0387)$ & $0.3631^{* * *}$ & $(0.0467)$ & & & $0.1868^{* * * *}$ & $(0.0305)$ & $0.1708^{* * * k}$ & $(0.0291)$ \\
\hline Staff Pick & $0.8522^{* * *}$ & $(0.0483)$ & $0.5302^{* \ldots *}$ & $(0.0546)$ & & & $0.5742^{* * *}$ & $(0.0251)$ & $0.5544^{* * *}$ & $(0.0200)$ \\
\hline Quick Update & $1.1235^{* * *}$ & $(0.0477)$ & $2.3413^{* \ldots *}$ & $(0.0939)$ & & & $2.2156^{* * *}$ & $(0.0587)$ & $2.0368^{* * * *}$ & $(0.0688)$ \\
\hline US Dummy & 0.0959 & $(0.0584)$ & -0.0804 & $(0.1563)$ & & & 0.1166 & $(0.0832)$ & 0.0830 & $(0.0782)$ \\
\hline Industry Controls? & \multicolumn{2}{|c|}{ Yes } & \multicolumn{2}{|c|}{ Yes } & & & \multicolumn{2}{|c|}{ Yes } & \multicolumn{2}{|c|}{ Yes } \\
\hline Time dummies? & \multirow{2}{*}{\multicolumn{2}{|c|}{ Yes }} & \multicolumn{2}{|c|}{ Yes } & & & \multicolumn{2}{|c|}{ Yes } & \multicolumn{2}{|c|}{ Yes } \\
\hline Wald-Chi ${ }^{2}$ & & & & & 92,83 & & \multicolumn{2}{|c|}{$3.01 \mathrm{e}^{7 * k * k}$} & \multicolumn{2}{|c|}{$2.32 \mathrm{e}^{6 * \ldots k}$} \\
\hline $\mathrm{R}^{2}$ Within/AR Test (1) & \multicolumn{2}{|c|}{0.0863} & \multicolumn{2}{|c|}{0.2543} & & & \multicolumn{2}{|c|}{$-10.62^{* * *}$} & \multicolumn{2}{|c|}{$-10.33^{* * *}$} \\
\hline $\mathrm{R}^{2}$ Between/AR Test (2) & \multicolumn{2}{|c|}{0.6513} & \multicolumn{2}{|c|}{0.1248} & & & & & \multicolumn{2}{|c|}{-1.40} \\
\hline $\mathrm{R}^{2}$ Overall/Sargan Test(p-value) & \multicolumn{2}{|c|}{0.6310} & \multicolumn{2}{|c|}{0.1474} & 152.4 & & \multicolumn{2}{|c|}{$\begin{array}{c}-0.43 \\
161.31(1.00)\end{array}$} & \multicolumn{2}{|c|}{$167.93(1.00)$} \\
\hline Observations & \multicolumn{2}{|c|}{16,078} & \multicolumn{2}{|c|}{16,078} & & & \multicolumn{2}{|c|}{16,078} & & \\
\hline Number of Entrepreneurs & & & & & & & & & & \\
\hline Estimator & Random & s OLS & Fixed E & OLS & Arellano & DPD & Arellano & DPD & Arellano & $1 \mathrm{DPD}$ \\
\hline
\end{tabular}

In Model I we estimate a random effects panel ordinary least squares model and report the corresponding R2 (within, between, overall). In Model II we estimate a fixed effects panel ordinary least squares

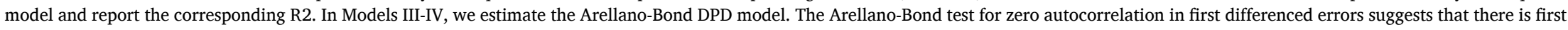
order serial correlation of the differenced errors but not a second order correlation. The Sargan test suggests that the overidentifying restrictions are valid.

* $p$-value $<0.10$.

** p-value $<0.05$. p-value $<0.01$. 
significant differences among these serial entrepreneurs in terms of their average campaign goal and campaign content. Serial crowdfunders with three or more projects tend on average to solicit less capital, receive more comments from backers, but do fewer updates, have less media content in their campaigns, and run shorter campaigns.

Table 4 presents the descriptive statistics, correlations, and variance inflation factors (VIFs) for the sample of serial crowdfunders with three or more launched campaigns. The means presented are the raw mean values before transformation, while the correlation coefficients are for the transformed values. From the correlation matrix we note that the two independent variables (Preparation Time and Project Goal), proposed as possible explanations for serial crowdfunders' performance, are significantly positively correlated with Amount Raised. This is consistent with the assumptions made in our theoretical section, above. In general, the correlations between the control variables and campaign performance are in line with those presented in prior literature. The average variance inflation factor, VIF, (1.33) and the maximum VIF (1.96) are well below the thresholds established in the literature (Hair et al., 2010; McDonald and Moffitt, 1980; Neter et al., 2018; Tabachnick and Fidell, 2007). Therefore, we have few concerns about multicollinearity in our subsequent analyses.

The average preparation time for campaigns in our sample of serial crowdfunders is 37 days. The average campaign in our sample raises $\$ 17,300$ during a campaign period of 33 days. On average, entrepreneurs wait 171 days before launching a subsequent campaign and the subsequent campaign is usually launched in the same industry. On average, the textual similarity between current and previous campaign is $17 \%$. In our sample of serial crowdfunders, entrepreneurs on average launch a campaign with a social capital stock of 533 comments. The average campaign has a video pitch where the entrepreneur pitches the project to potential backers; includes eight images in its content section; and offers nine different rewards. In $29 \%$ of campaigns, the entrepreneur updates backers on the progress of the campaign during the first three days of the campaign. Of campaigns launched by serial crowdfunders, only $14 \%$ are featured by Kickstarter's staff.

\section{Results}

Table 5 starts by presenting the results of the dynamic OLS estimator before estimating the Arellano-Bond dynamic panel data model. In Column (I), the (upward biased) random effects OLS estimator shows that previous performance is positively associated with current performance, while in Column (II), the (downward biased) fixed effects OLS estimator shows that previous performance is negatively associated with current performance. This conflict in the results is not surprising since Nickell (1981) argued that dynamic OLS estimators are biased. To overcome this issue we run the unbiased Arellano-Bond estimator in Columns (III-V). As expected, the unbiased Arellano-Bond estimates are bounded above by the coefficient of the lagged dependent variable in Column (I) and bounded below by the coefficient of the lagged dependent variable in Column (II).

Column (III) presents the coefficient of the lagged dependent variable excluding campaign-specific controls while controlling for time and industry effects. Column (IV) adds time varying controls related to project goal, campaign content (rewards, video pitch, video content, images, text length, and duration), campaign quality (staff pick), quick update by the entrepreneur, and whether the current project is located in the US. Column (V) adds controls related to previous crowdfunding endeavors: social capital accumulated over previous campaigns, whether the entrepreneur changed industry in their current project, the time elapsed between the current and previous venture, and the similarity between current and previous project.

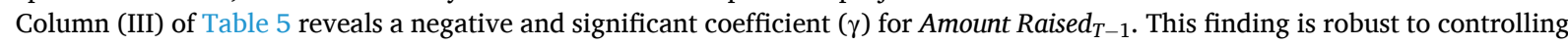
for various campaign factors that were shown to be significant drivers of campaign performance (Column IV - Column V). It is consistent with a cyclical performance trajectory which suggests that under-performance follows over-performance and vice-versa. The estimated coefficient of -0.0443 in Column (III) means that a $10 \%$ increase in the amount of capital raised in the previous campaign is associated with a $0.443 \%$ decrease in the amount of capital raised in the current campaign. Given that $-1<\gamma<0$, the cycles dampen and serial crowdfunders' performance cycles around their long-run value and eventually converges towards it. As for the control variables, their effects on crowdfunding campaign performance are generally in line with prior research (Colombo et al., 2015; Courtney et al., 2017; Mollick, 2014; Scheaf et al., 2018).

Given the evident cyclicality in serial crowdfunders' performance, we next go on to test Propositions 1 and 2 . To do so, we adopt a two-stage empirical strategy. The first stage investigates whether the variables Preparation Time and Project Goal exhibit cyclical trajectories, while the second stage investigates whether these variables are significantly positively associated with fundraising performance, as hypothesized. If some of these variables do not exhibit the required trajectory or are not positively associated with performance, we can rule out the relevant underlying mechanism as a possible explanation for the exhibited performance. To assist the reader, Table 6 summarizes the conditions corresponding to the two stages of our empirical analysis that need to be met before concluding that either of Propositions 1 or 2 hold.

To implement the first stage of the empirical analysis, we re-ran the Arellano-Bond model using Preparation Time and Project Goal as dependent variables. The model specifications inclusive of control variables are:

$$
\begin{aligned}
& \text { (i) Preparation Time } \text { Ti,T }=\alpha_{i}+\gamma \cdot \text { Preparation Time }_{i, T-1}+\beta \cdot X_{i, T}+\varepsilon_{i, T} \\
& \text { (ii) Project Goal }{ }_{i, T}=\alpha_{i}+\gamma \cdot \text { Project Goal }_{i, T-1}+\beta \cdot X_{i, T}+\varepsilon_{i, T}
\end{aligned}
$$

Table 7 presents the results. Column I of Table 7 shows that our measure of serial entrepreneur effort, Preparation Time, exhibits a cycling trajectory $(\gamma=-0.0301 ; p<0.01)$. This is consistent with Proposition 1 , and the underlying mechanism of entrepreneurs' dynamic effort signaling positive reputations. Column II shows that Project Goal exhibits a positive trajectory $(\gamma=0.0361 ; p<0.01)$. 
Table 6

Overview of the two-stage empirical testing strategy.

\begin{tabular}{|c|c|c|c|c|c|c|}
\hline & \multicolumn{4}{|c|}{ First - Stage } & \multirow{2}{*}{\multicolumn{2}{|c|}{$\frac{\text { Second-Stage }}{\text { Dependent Variable: }}$}} \\
\hline & \multicolumn{4}{|c|}{ Dependent Variables: } & & \\
\hline & \multicolumn{2}{|c|}{ Preparation Time ${ }_{\mathrm{T}}$} & \multicolumn{2}{|c|}{ Project Goal $_{\mathrm{T}}$} & \multicolumn{2}{|c|}{ Amount Raised $_{\mathrm{T}}$} \\
\hline \multicolumn{7}{|l|}{ Independent Variables: } \\
\hline Preparation Time $_{\mathrm{T}}$ & $(-)$ & Proposition 1 & & & $(+)$ & Proposition 1 \\
\hline Project Goal $_{\mathrm{T}}$ & & & $(-)$ & Proposition 2 & $(+)$ & Proposition 2 \\
\hline
\end{tabular}

Table 7

Checking for cyclicality of preparation time and project goal.

\begin{tabular}{|c|c|c|c|c|}
\hline \multirow[t]{2}{*}{ Dependent Variable: } & \multicolumn{2}{|c|}{ Preparation Time $_{\mathrm{T}}$} & \multicolumn{2}{|c|}{ Project Goal ${ }_{\mathrm{T}}$} \\
\hline & \multicolumn{2}{|c|}{ I } & \multicolumn{2}{|c|}{ II } \\
\hline Preparation Time $_{\mathrm{T}-1}$ & $-0.0301 * * *$ & $(0.0032)$ & & \\
\hline Project Goal ${ }_{\mathrm{T}-1}$ & & & $0.0361^{* * *}$ & $(0.0034)$ \\
\hline Industry Change & $0.0567^{*}$ & $(0.0294)$ & $0.0221^{* \ldots *}$ & $(0.0040)$ \\
\hline Project Similarity & $-0.9108^{* * *}$ & $(0.0274)$ & $-0.3566^{* * *}$ & $(0.0228)$ \\
\hline Rewards & $0.2060^{* \ldots * *}$ & $(0.0135)$ & $0.4646^{* * *}$ & $(0.0088)$ \\
\hline Video Pitch & $0.3080^{* * *}$ & $(0.0199)$ & $0.1584^{* * *}$ & $(0.0123)$ \\
\hline Video Count & $0.0582^{* * *}$ & $(0.0089)$ & $0.1090 * * *$ & $(0.0055)$ \\
\hline Image Count & $0.0564 * * *$ & $(0.0061)$ & $0.0441^{* * *}$ & $(0.0064)$ \\
\hline Text Length & $0.0638^{* * *}$ & $(0.0080)$ & $0.1689^{* * *}$ & $(0.0075)$ \\
\hline Duration & 0.3437 \%** & $(0.0149)$ & $0.9080^{* \ldots *}$ & $(0.0084)$ \\
\hline Wald-Chi ${ }^{2}$ & \multicolumn{2}{|c|}{$63,956.58^{* \cdots * k}$} & \multicolumn{2}{|c|}{$4.15 \mathrm{e}^{6 * * *}$} \\
\hline AR Test (1) & \multicolumn{2}{|c|}{$-22.49^{* * *}$} & \multicolumn{2}{|c|}{$-14.41^{* * *}$} \\
\hline AR Test (2) & \multicolumn{2}{|c|}{-1.13} & \multicolumn{2}{|c|}{-0.23} \\
\hline Sargan Test (p-value) & \multicolumn{2}{|c|}{$156.28(1.00)$} & \multicolumn{2}{|c|}{$163.56(1.00)$} \\
\hline Observations & \multicolumn{2}{|c|}{16,078} & \multicolumn{2}{|c|}{16,078} \\
\hline Number of Entrepreneurs & \multicolumn{2}{|c|}{7672} & \multicolumn{2}{|c|}{7672} \\
\hline
\end{tabular}

In Models I-II, the Arellano-Bond test for zero autocorrelation in first differenced errors suggests that there is first order serial correlation of the differenced errors but not a second order correlation. The Sargan test suggests that the overidentifying restrictions are valid.

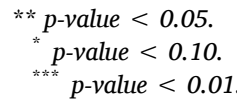

Table 8

Dynamic panel data model: the role of project goal and preparation time on campaign performance.

\begin{tabular}{|c|c|c|c|c|c|c|}
\hline \multirow[b]{3}{*}{ Amount Raised $_{\mathrm{T}-1}$} & \multicolumn{6}{|c|}{ Dependent Variable: Amount Raised ${ }_{\mathrm{T}}$} \\
\hline & \multicolumn{2}{|c|}{$\mathrm{I}$} & \multicolumn{2}{|c|}{ II } & \multicolumn{2}{|c|}{ III } \\
\hline & $-0.0956^{* * *}$ & $(0.0027)$ & $-0.0870^{* * *}$ & $(0.0038)$ & $-0.0962^{* * *}$ & $(0.0042)$ \\
\hline Preparation Time $_{\mathrm{T}}$ & & & $0.0711^{* * *}$ & $(0.0072)$ & $0.0425^{* * *}$ & $(0.0063)$ \\
\hline Project Goal $_{\mathrm{T}}$ & $0.2133^{* * *}$ & $(0.0066)$ & & & $0.2056^{* * *}$ & $(0.0077)$ \\
\hline Social Capital & $-0.2713^{* * *}$ & $(0.0159)$ & $-0.2737^{* \cdots *}$ & $(0.0153)$ & $-0.2762^{* * *}$ & $(0.0155)$ \\
\hline Industry Change & $-0.2324 * * *$ & $(0.0335)$ & $-0.1828^{* * *}$ & $(0.0323)$ & $-0.2199^{* * *}$ & $(0.0317)$ \\
\hline Time Since Last Project & $-0.0435^{* * *}$ & $(0.0087)$ & $-0.0553^{* * *}$ & $(0.0089)$ & $-0.0580^{* * *}$ & $(0.0103)$ \\
\hline Project Similarity & $0.3714^{* * *}$ & $(0.0563)$ & $0.4070^{* * *}$ & $(0.0476)$ & $0.4193^{* * *}$ & $(0.0568)$ \\
\hline Staff Pick & $0.6417^{* * *}$ & $(0.0193)$ & $0.6838^{* * *}$ & $(0.0256)$ & $0.6268^{* * *}$ & $(0.0237)$ \\
\hline Quick Update & $2.3198^{* * *}$ & $(0.0533)$ & $2.2516^{* * *}$ & $(0.0610)$ & $2.2392^{* * *}$ & $(0.0642)$ \\
\hline US Dummy & $0.1790 * * *$ & $(0.0680)$ & $0.1679^{* * * *}$ & $(0.0702)$ & $0.1950^{* * *}$ & $(0.0618)$ \\
\hline Industry Controls? & \multicolumn{2}{|c|}{ Yes } & \multicolumn{2}{|c|}{ Yes } & \multicolumn{2}{|c|}{ Yes } \\
\hline Time dummies? & \multicolumn{2}{|c|}{ Yes } & \multicolumn{2}{|c|}{ Yes } & \multicolumn{2}{|c|}{ Yes } \\
\hline Wald-Chi $^{2}$ & \multicolumn{2}{|c|}{$6.15 \mathrm{e}^{7 * * \cdots *}$} & \multicolumn{2}{|c|}{$661,697^{* * * *}$} & \multicolumn{2}{|c|}{$2.78 \mathrm{e}^{6 * * *}$} \\
\hline AR Test (1) & \multicolumn{2}{|c|}{$-10.45^{* * * *}$} & \multicolumn{2}{|c|}{$-10.76^{* * *}$} & \multicolumn{2}{|c|}{$-10.49^{* * *}$} \\
\hline AR Test (2) & \multicolumn{2}{|c|}{-1.49} & \multicolumn{2}{|c|}{-1.15} & \multicolumn{2}{|c|}{-1.50} \\
\hline Sargan Test (p-value) & \multicolumn{2}{|c|}{$168.81(1.00)$} & \multicolumn{2}{|c|}{$160.32(1.00)$} & \multicolumn{2}{|c|}{$165.78(1.00)$} \\
\hline Observations & \multicolumn{2}{|c|}{16,078} & \multicolumn{2}{|c|}{16,078} & \multicolumn{2}{|c|}{16,078} \\
\hline Number of Entrepreneurs & \multicolumn{2}{|c|}{7672} & \multicolumn{2}{|c|}{7672} & \multicolumn{2}{|c|}{7672} \\
\hline
\end{tabular}

In Models I-III, the Arellano-Bond test for zero autocorrelation in first differenced errors suggests that there is first order serial correlation of the differenced errors but not a second order correlation. The Sargan test suggests that the overidentifying restrictions are valid.

$*$ p-value $<0.10$.

** p-value $<0.05$.

p-value $<0.01$. 
Table 9

Robustness checks: controlling for possible selection bias (Models I - II) and using alternative measures of success (Models III - VI).

\begin{tabular}{|c|c|c|c|c|c|c|c|c|c|c|c|c|}
\hline \multirow{4}{*}{$\begin{array}{l}\text { Dependent Variable: } \\
\text { Dependent Variable }_{\mathrm{T}-1} \\
\text { Preparation Time }_{\mathrm{T}}\end{array}$} & \multicolumn{4}{|c|}{ Amount Raised ${ }_{\mathrm{T}}$} & \multicolumn{4}{|c|}{ Funding Ratio ${ }_{\mathrm{T}}$} & \multicolumn{4}{|c|}{ Successful Amount Raised ${ }_{\mathrm{T}}$} \\
\hline & \multicolumn{2}{|c|}{ I } & \multicolumn{2}{|c|}{ II } & \multicolumn{2}{|c|}{ III } & \multicolumn{2}{|c|}{ IV } & \multicolumn{2}{|c|}{$\mathrm{V}$} & \multicolumn{2}{|c|}{ VI } \\
\hline & $-0.0946^{* * *}$ & $(0.0039)$ & $-0.0988^{* * *}$ & $(0.0041)$ & $-0.0599 * * *$ & $(0.0034)$ & $-0.0581^{* * *}$ & $(0.0035)$ & $-0.0768^{* * *}$ & $(0.0045)$ & $-0.0891^{* * *}$ & $(0.0048)$ \\
\hline & & & $0.0409^{* * *}$ & $(0.0074)$ & & & $0.0158^{* * *}$ & $(0.0032)$ & & & $0.0270^{* *}$ & $(0.0154)$ \\
\hline Project Goal ${ }_{\mathrm{T}}$ & $0.1016 \ldots$ & $(0.0149)$ & $0.2094^{* * *}$ & $(0.0083)$ & $-0.3605^{* * *}$ & $(0.0050)$ & $-0.3066 * * *$ & $(0.0051)$ & $-0.6290^{* \cdots *}$ & $(0.0192)$ & $-0.5388^{* * *}$ & $(0.0183)$ \\
\hline Inverse Mills Ratio & $0.2563^{* * *}$ & $(0.0231)$ & $0.2991^{* * *}$ & $(0.0158)$ & $0.0920^{* * *}$ & $(0.0125)$ & $0.1036^{* * *}$ & $(0.0108)$ & $0.2921^{* \cdots *}$ & $(0.0325)$ & $0.3177^{* \ldots *}$ & $(0.0276)$ \\
\hline Campaign-Specific Controls? & \multicolumn{2}{|c|}{ Yes } & \multicolumn{2}{|c|}{ Yes } & \multicolumn{2}{|c|}{ Yes } & \multicolumn{2}{|c|}{ Yes } & \multicolumn{2}{|c|}{ Yes } & \multicolumn{2}{|c|}{ Yes } \\
\hline Industry Controls? & \multirow{2}{*}{\multicolumn{2}{|c|}{ Yes }} & \multicolumn{2}{|c|}{ Yes } & \multicolumn{2}{|c|}{ Yes } & \multicolumn{2}{|c|}{ Yes } & \multicolumn{2}{|c|}{ Yes } & \multicolumn{2}{|c|}{ Yes } \\
\hline Time dummies? & & & \multirow{2}{*}{\multicolumn{2}{|c|}{$\begin{array}{c}\text { Yes } \\
519,559^{* * *}\end{array}$}} & & & \multirow{2}{*}{\multicolumn{2}{|c|}{$\begin{array}{c}\text { Yes } \\
388,972^{* * *}\end{array}$}} & \multirow{2}{*}{\multicolumn{2}{|c|}{$\begin{array}{c}\text { Yes } \\
1.37 \mathrm{e}^{7 * * *}\end{array}$}} & \multirow{2}{*}{\multicolumn{2}{|c|}{$\begin{array}{c}\text { Yes } \\
131,259^{* * * *}\end{array}$}} \\
\hline Wald-Chi ${ }^{2}$ & \multicolumn{2}{|c|}{$352,412^{* * *}$} & & & \multicolumn{2}{|c|}{$2.59 \mathrm{e}^{6 * * *}$} & & & & & & \\
\hline AR Test (1) & \multicolumn{2}{|c|}{$-10.00^{* * *}$} & \multicolumn{2}{|c|}{$-10.23^{* * *}$} & \multicolumn{2}{|c|}{$-13.93^{* * *}$} & \multicolumn{2}{|c|}{$-13.48^{* * * *}$} & \multicolumn{2}{|c|}{$-19.35^{* * *}$} & \multicolumn{2}{|c|}{$-19.43^{* * *}$} \\
\hline AR Test (2) & \multicolumn{2}{|c|}{-1.47} & -1. & & & & -0. & & -2 & & -2 . & \\
\hline Sargan Test (p-value) & 167.91 & .00) & 167.37 & .00) & 178.95 & .00) & 174.43 & .00) & 150.23 & .00) & 149.94 & .00) \\
\hline Observations & $16, \mathrm{C}$ & & 16, & & & & $16, \mathrm{C}$ & & 16 , & & 16, & \\
\hline Number of Entrepreneurs & 76 & & 76 & & & & 76 & & 76 & & 76 & \\
\hline
\end{tabular}

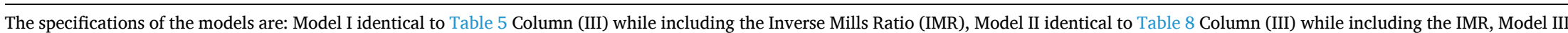

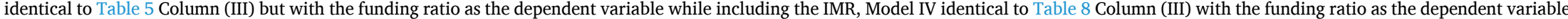

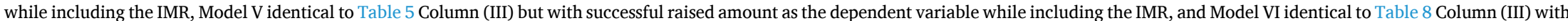
the successful raised amount as the dependent variable while including the IMR.

* $p$-value $<0.10$.

$$
\text { ***:value }<0.05 \text {. }
$$

**** palue $<0.01$ 
The amount of funds requested by the entrepreneur on the platform remains above the long run average of the funds requested and eventually converges towards it. This is inconsistent with Proposition 2, and the underlying mechanism of backers screening for hidden over-bidders based on their sequence of campaign goals.

Having established initial support for Propositions 1, we next proceed to the second stage of the empirical strategy. Referring to the second panel of Table 6, we investigate whether effort supplied by the serial crowdfunder to the current project is positively associated with amounts raised. Table 8 presents the results, using a full set of control variables. Specifications II and III confirm this prediction of Proposition 1, with a positive and significant estimated coefficient on the Preparation Time variable. That is, the longer the entrepreneur prepares the campaign for launch, the better the performance of the entrepreneur's campaign (Chrisman et al., 2005; Kunz et al., 2017). Given the support for Proposition 1 in both stages of the empirical analysis, we infer that the mechanism of entrepreneurs' dynamic effort signaling positive reputations helps explain the cyclical performance exhibited by serial crowdfunders.

To ensure the validity of our findings before drawing out implications of the results in the closing section of the paper, we next run some specification checks and robustness tests.

\subsection{Specification checks}

Two tests are necessary after an Arellano and Bond estimation to check the validity of the model: the Arellano-Bond autocorrelation tests and the Sargan test for joint validity of instruments. First, the Arellano-Bond autocorrelation test checks for the first- and secondorder serial correlation in the idiosyncratic disturbances. For a model to be valid, there should be first-order serial correlation due to the lagged dependent variable - but no second-order serial correlation. For all the models presented in our analysis we report the firstorder, AR(1) and second-order, AR(2), autocorrelation tests. The first-order autocorrelation statistics in the tables are all significant: thus, we reject the null hypothesis that there is no first-order serial correlation. The second-order autocorrelation statistics are not significant: thus, we fail to reject the null hypothesis that there is no second-order autocorrelation. These results therefore support the validity of the specified model (Arellano and Bond, 1991).

Second, the Sargan test checks the validity of the instruments, as one of the main assumptions in GMM is that all instruments are exogeneous in nature. It is performed after the two-step estimation. The null hypothesis of this test is that the over-identifying restrictions of the model are valid. We report the value of the Sargan statistic in the tables. The $p$-values of this statistic exceed conventional Type I errors and so do not reject the null hypothesis, suggesting that the model specifications are valid (Arellano and Bond, 1991; Sargan, 1958). The estimations performed do not use White's correction for heteroscedasticity to generate robust standard errors since the Sargan test cannot be performed if the model was specified with robust standard errors. To ensure the robustness of our results, we repeated all the analyses performed using White's correction for heteroscedasticity to generate the robust standard errors; our results (available upon request) were qualitatively unchanged.

\subsection{Robustness checks}

When analyzing serial entrepreneurs, one might be concerned that selection bias could affect the consistency and generalizability of the findings (Chen, 2013). Although our analysis is performed on the population of serial crowdfunders on Kickstarter, there might still exist heterogeneities between these serial crowdfunders in terms of their campaign launching activity (three vs four campaigns, four vs five campaigns etc.). Additionally, our analysis only includes serial entrepreneurs with three and more projects who might differ from serial entrepreneurs with only two projects (see Table 3). Econometric theory predicts that individual-based selection bias should pose no concerns when using the Arellano-Bond estimation process and that it yields consistent results because individual characteristics are eliminated in the differencing process (Al-Sadoon et al., 2019). However, as a first robustness check, and to address possible concerns, we check the consistency of our results by using the Heckman two-step correction for selection bias.

We first use a probit model to estimate the entrepreneur's probability of launching a subsequent campaign given the current campaign outcome. This generates the inverse Mills ratio which is then included as an independent variable in the DPD estimation model. Columns I and II of Table 9 present the results. The coefficient of the inverse Mills ratio is statistically significant; however, this finding does not challenge the consistency property of the Arellano-Bond estimator; and including the inverse Mills ratio does not affect any of the coefficients in terms of magnitude, direction, or significance. This provides additional support for the notion that the Arellano-Bond estimator yields consistent results and is unaffected by selection bias.

As a second robustness check and to ensure the validity of our results, we run a panel vector autoregression (VAR) model. VAR

Table 10a

Panel Vector Autoregression (VAR) Model.

\begin{tabular}{|c|c|c|c|c|}
\hline \multirow{2}{*}{$\begin{array}{l}\text { Dependent Variable: } \\
\text { Amount Raised }{ }_{\mathrm{t}-1}\end{array}$} & \multicolumn{2}{|c|}{ Amount Raised ${ }_{t}$} & \multicolumn{2}{|c|}{ Preparation Time $_{\mathrm{t}}$} \\
\hline & $-0.3381^{* * *}$ & $(0.0482)$ & $-0.2105^{* * *}$ & $(0.0421)$ \\
\hline Preparation Time ${ }_{t-1}$ & $-0.1910^{* * *}$ & $(0.0374)$ & $-0.0990^{* * *}$ & $(0.0322)$ \\
\hline Observations & \multicolumn{2}{|c|}{16,078} & \multicolumn{2}{|c|}{16,078} \\
\hline Number of Entrepreneurs & \multicolumn{2}{|c|}{7672} & \multicolumn{2}{|c|}{7672} \\
\hline
\end{tabular}


models have been widely used to explain the dynamic behavior of economic and financial indicators over time (Ang and Piazzesi, 2003; Cochrane, 1994; Shan, 2005). Given that our variables are dynamically interdependent, a VAR model could help us not only estimate the dynamic relationship of one variable on lagged values of itself, but also other variables that are potentially endogenous. The results of the VAR model are reported in Table 10a. They show that lagged values of both Amount Raised and Preparation Time are negatively associated with current values of these variables. This provides further support for Proposition 1 that high performance and high effort levels are followed by low performance and low effort levels. A Granger causality test further validates the bidirectional relationship between Amount Raised and Preparation time. Table 10b contains test statistics which decisively reject the null hypothesis of no relationships.

As a third robustness check, we investigate whether our results also hold for different measures of performance. Several papers have used ratio-based measures to gauge campaign performance (Belleflamme et al., 2013; Cholakova and Clarysse, 2015; Frydrych et al., 2014; Scheaf et al., 2018). Hence, we try using a campaign's funding ratio as an alternate measure of campaign performance which is operationalized as the inverse hyperbolic sine transformation of [(Amount Raised)/(Funding Goal)]. According to this measure, among successful projects those projects with a higher funded percentage are more successful than those which barely met their goals, while for unsuccessful projects, those projects that were closer to meeting their goals are more successful than those that were further from meeting their goals. We repeat the main DPD analysis using this measure and summarize the main results in Columns III and IV of Table 9.

The results indicate that, compared with the main analysis with Amount Raised as the dependent variable, Project Goal exhibits the opposite relationship with Funding Ratio. This difference stems from the operationalization of the Funding Ratio, which is the Amount Raised relative to the Project Goal. It is intuitive that the declared goal would exhibit such a negative relationship with the funding ratio. Otherwise, the coefficient estimates in Columns III and IV of Table 9 are not qualitatively different from those presented in Tables 5 and 8. We also repeat the analysis for Successful Amount Raised (a continuous variable that takes the value 0 in the case the campaign was unsuccessful and takes the value of amount raised if the campaign was successful). The results, presented in Columns V and VI, are again qualitatively unchanged from before. This reassures us that the finding of cyclical performance is not sensitive to the dependent variable used in the main analysis.

Fourth, it is possible that an entrepreneur might abandon a project and return to it at a later time, resulting in a prolonged preparation time. More generally, Preparation Time might not correspond exactly to the time involved in working on a campaign, since it omits preparation undertaken before the project is created, the content is loaded, and the campaign is launched. Indeed, projects which are meticulously planned and developed may be rapidly created, uploaded, and launched. However, this is unlikely to create estimation bias because the fixed effects dynamic panel data model controls for idiosyncratic individual-specific habits relating to the campaign preparation process. Entrepreneurs with a systematic tendency to allocate less time per day of preparation should continue to allocate less time per day of preparation in their subsequent campaigns. The fixed effects estimator is a 'within' estimator, analyzing differences within an entrepreneur's campaigns, not differences between entrepreneurs; hence this idiosyncratic effect is differenced out in the estimation procedure, leaving the econometric estimates free of bias. Moreover, Table 7 showed that an increase in project similarity between the current and previous project (which presumably calls before less effort) reduces the amount of preparation time required. This is what would be expected if preparation time measures effort, and instills confidence in the appropriateness of our proxy as a measure of effort that encompasses the different activities related to campaign construction.

Nevertheless, as a further robustness check we investigate whether alternative measures of effort have similar effects. Table 11 reports the estimated trajectories of different campaign content factors that are also related to effort: the number of rewards, video count, image count, and text length. The estimates show that all these factors exhibit a cyclical trajectory, providing additional support to our main findings.

Fifth, our main analysis assumed that the cyclical behavior of serial crowdfunders' performance is symmetric. However, entrepreneurs may react differently to success and failure. For example, if serial crowdfunders are more 'proactive' following failure than following success, their performance should exhibit stronger cycles following failure and weaker cycles following success. To explore this possibility, we split the sample into campaigns following failure, and campaigns following success, and re-ran the models presented in Table 5. In unreported results (available on request), we found that the negative lagged performance outcome was indeed larger in absolute terms for crowdfunders who failed first, than for those who succeeded first. This provides some support for a 'proactivity' impetus; but in all other respects, the results are similar to before.

A sixth robustness check was conducted to tackle possible biases arising from the inclusion, in the sample, of entrepreneurs with 'non-serious' crowdfunding efforts or 'money grab' attempts. Similar to Mollick (2014), we eliminated from the sample those entrepreneurs with project goals less than $\$ 100$ and more than $\$ 1,000,000$. We also eliminated money grab attempts where following failure a crowdfunder relaunches with a lower declared goal. This leaves us with 22,687 crowdfunding campaigns launched by 7195 serial crowdfunders. We re-ran our main analysis on this dataset and the results were consistent with the findings presented earlier. Campaign performance still exhibits a cycling pattern and is explained by cyclical effort which is positively associated with

Table 10b

Granger causality test.

\begin{tabular}{|c|c|c|c|c|c|c|c|}
\hline Eq. (1) & Excluded & Chi- squared & p-value & Eq. (2) & Excluded & Chi- squared & p-value \\
\hline \multicolumn{4}{|l|}{ Amount Raised } & \multicolumn{4}{|c|}{ Preparation Time } \\
\hline & Peparation Time & 25.973 & 0.000 & & Amount Raised & 25.058 & 0.000 \\
\hline
\end{tabular}


Table 11

Trajectory of different effort proxies.

\begin{tabular}{|c|c|c|c|c|c|c|c|}
\hline \multirow[t]{2}{*}{ Dependent Variable: } & Rewards $_{\mathrm{T}}$ & \multicolumn{2}{|c|}{ Video Count ${ }_{T}$} & \multicolumn{2}{|c|}{ Image Count ${ }_{\mathrm{T}}$} & \multicolumn{2}{|c|}{ Text Length ${ }_{\mathrm{T}}$} \\
\hline & I & \multicolumn{2}{|c|}{ II } & \multicolumn{2}{|c|}{ III } & \multicolumn{2}{|c|}{ IV } \\
\hline Dependent Variable $_{\mathrm{T}-1}$ & $-0.0506^{* * *}$ & $-0.3374 * * *$ & $(0.0014)$ & $-0.0780 * * *$ & $(0.0001)$ & $-0.0924 * * *$ & $(0.0004)$ \\
\hline Wald-Chi ${ }^{2}$ & $6895.40 * * *$ & \multicolumn{2}{|c|}{$59,347.17^{* * *}$} & \multicolumn{2}{|c|}{$402,253.56^{* * *}$} & \multicolumn{2}{|c|}{$46,299.77 * * *$} \\
\hline Observations & 16,078 & \multicolumn{2}{|c|}{16,078} & \multicolumn{2}{|c|}{16,078} & \multicolumn{2}{|c|}{16,078} \\
\hline Number of Entrepreneurs & 7672 & \multicolumn{2}{|c|}{7672} & \multicolumn{2}{|c|}{7672} & \multicolumn{2}{|c|}{7672} \\
\hline
\end{tabular}

* p-value $<0.10$.

$*$ *value $<0.05$.

$* * *$ p-value $<0.01$.

performance. As a seventh check, we removed outliers from the sample. We trimmed the data at the $1 \%$ level and eliminated entrepreneurs with more than 20 launched campaigns. We repeated our analysis and found no significant changes in the results when the outliers were dropped from our sample. Overall, these seven checks give us some confidence in the robustness of the results.

\section{Discussion and conclusion}

This paper contributes to the literature on serial crowdfunding by analyzing serial crowdfunders' performance over several successive fundraising campaigns. Drawing on the entrepreneurial finance literature, we discussed the implications of asymmetric information about hidden entrepreneurial actions and hidden entrepreneurial types for serial crowdfunders' dynamic fundraising performance. This generated a prediction that serial crowdfunders' performance cycles around its (idiosyncratic) long-term average, and eventually converges towards it. A sample of data on serial crowdfunders on the Kickstarter platform generated empirical support for this prediction, and for the argument that effort-based signaling and reputation can explain it. Thus, following an over-performing crowdfunding campaign, entrepreneurs can afford to supply somewhat less costly effort to the next campaign without unduly damaging their reputation with backers, resulting in underperformance; but this underperformance stimulates entrepreneurs to exert higher levels of effort next time to restore their reputation, leading to over-performance. Our empirical findings appear to be robust to different model specifications and sample selection bias.

This paper makes a twofold contribution to the literature and raises several implications for scholars. First, it adds to the growing literature on serial crowdfunding by moving beyond comparing novice and serial crowdfunders, instead exploring how and why serial crowdfunders adjust their behavior over time and the resulting implications for fundraising performance. Dynamic analyses are known to be capable of revealing underlying mechanisms about entrepreneurial behavior, including whether entrepreneurs learn and how rapidly they do so (Parker, 2006). The dynamic analysis performed here helped distinguish between two distinct mechanisms as drivers of fundraising performance. More generally, we suspect that there are other situations where dynamic outcomes can reveal hidden facets of underlying entrepreneurial behavior. For example, there might be applications to pitching of new venture ideas to equity investors, with learning and effort adjustments taking place both within and across venture pitches (Poczter and Shapsis, 2018; Smith and Viceisza, 2018).

Second, our empirical findings suggest that signaling based on effort and reputation are key determinants of crowdfunders' fundraising initiatives, and that dynamic variations in effort drives cycles in serial crowdfunders' fundraising performance. This raises several intriguing questions about crowdfunders' reputations and reputation management, which has to date garnered surprisingly little attention in the crowdfunding literature (Li and Martin, 2019). The closest that prior research has come to exploring the dynamic role of reputation in the entrepreneurial finance literature relates to: the reputations of venture capital firms (Gompers, 1996; Nahata, 2008); information reporting to investors (Beshears et al., 2017); and 'relationship banking' (Berger and Udell, 1995; Petersen and Rajan, 1994), where successful entrepreneurial borrowers who build reputations over time are rewarded with more favorable lending terms. By leveraging the crowdfunding data where we have access to both successful and unsuccessful financing rounds, we have taken a different tack in investigating the dynamic role of effort and reputation on the performance of multiple rounds. We note that since effort is costly, the entrepreneur's reputation on the platform need not grow monotonically over time. Specifically, following superior performance the entrepreneur could coast on their reputation and supply less effort to the current campaign; they can then restore their reputation by expending greater effort on the subsequent campaign. We believe that the drivers and dynamics of crowdfunders' reputations should be explored more systematically in future research. For example, we suspect that reputation management may also be important for other sources of entrepreneurial finance, such as family finance (Basu and Parker, 2001; Sieger and Minola, 2017), where ongoing relationships also impart a dynamic character to financing choices.

This paper also carries implications for practice. For instance, if an entrepreneur anticipates wanting to launch a blockbuster future project about which they are especially passionate, our results would recommend them to exert higher effort than they might otherwise supply to that project's predecessor. That would proactively build a positive reputation which would maximize the future project's chances of getting funded. Additionally, our results suggest that serial crowdfunders may want to develop industry-specific knowledge by launching campaigns in the same industry, since changing industry seems to adversely affect their fundraising performance. We also highlight the role of timely launches of new campaigns, since waiting for longer periods of time between campaigns seems to adversely affect funding outcomes as well.

Reward-based crowdfunding platform designers might also be interested in our results, since their revenues derive from a 
percentage of successfully raised funds. To maximize their revenues, most crowdfunding platforms maintain blogs which guide entrepreneurs about how to successfully launch a crowdfunding campaign. Since serial crowdfunders are becoming more common and represent a significant portion of the amounts raised on these platforms, our results suggest that platform operators might want to provide additional guidance to crowdfunders beyond their initial campaigns. Instructions helping crowdfunders to maintain their fundraising performance in subsequent campaigns, or how to reverse unfavorable funding outcomes, could be of great value to entrepreneurs and platform operators alike.

This paper is prone to several limitations that pave the way for further research. First, we measure reputation in terms of the amount of capital raised in the previous (and current) campaign. This is perhaps the most easily accessible signal of reputation on the platform that backers can obtain. However, we acknowledge that there are multiple dimensions of reputation that we do not account for in this paper. For example, did the entrepreneur deliver the product on time, and did the entrepreneur fulfill the promises made during the campaign? These reputational dimensions are not as visible and possibly not quite as easy to observe by backers as the one we focus on; but we believe that incorporating them could provide a fuller representation of the role of reputation in the serial crowdfunding context - a topic deserving of closer scholarly investigation (Li and Martin, 2019).

Second, the current models proposed do not account for external stimuli that could affect entrepreneurs' choices between campaigns. Indeed, when making choices between campaigns, entrepreneurs may internalize external factors in their decision process. For instance, anticipating that it was harder to secure funding during the Covid-19 pandemic, entrepreneurs might have reacted by supplying more effort to current campaigns regardless of their reputation on the platform. That could weaken the cyclicality of dynamic effort and hence amounts raised. Although accounting for different external stimuli would enrich the model proposed and provide a fruitful avenue for future research, we believe that doing so is unlikely to nullify our results. That is because omitted variables pertaining to external stimuli would be correlated with current outcomes/decisions, but not with the lagged indicator - thereby avoiding omitted variable bias. Thus, while effort might be distorted in the short-term by shocks like Covid-19, the underlying relationship we estimated is likely to remain valid.

Third, we did not directly investigate the effects of learning on campaign performance and on the effort supplied to campaigns. Presumably, if learning drives the results, the finding of cyclical performance would go away upon including controls for similarity of current and previous campaigns, and whether the new campaign entails a change of industry. However, including these controls made no difference to the results, suggesting that learning is unlikely to be the driving force at work. On the other hand, we did find that following an unsuccessful campaign the subsequent increase in effort supplied to the next campaign is larger (in absolute terms) than the decrease in the effort supplied to future campaigns following success. The same holds for fundraising performance. Given the mixed evidence relating to the role of learning in the crowdfunding context (Butticè et al., 2018; Yang and Hahn, 2015), this is an avenue of research in need of further exploration.

Fourth, we cannot decisively rule out competing mechanisms that could also give rise to cyclical patterns in fundraising success. It could be that serial crowdfunders alternate periods of exploitation with exploration or choose some campaign characteristics in a cyclical fashion to maintain a base level of performance over time. Alternatively, cyclicality could also be driven by factors affecting backers' cyclical behavior (e.g., overhangs from prior projects, or cyclicality of potential supporter engagement). ${ }^{7}$ No doubt other possible mechanisms could also be proposed. Future research could usefully explore these and gather additional data to test them against the effort and reputation mechanism studied here. Until that happens, we must exercise due caution when interpreting our results.

Fifth, we track crowdfunders on only one crowdfunding platform: we lack information about whether they launched campaigns on other platforms as well. This raises two concerns: it might 1) underestimate the number of serial crowdfunders; and 2) undercount campaigns on other platforms launched by the serial crowdfunders in our sample. We do not know whether this will affect our results; but some extant evidence suggests the impact may be limited, since it appears that crowdfunders who were successful on one platform usually launch subsequent campaigns on the same platform (Butticè et al., 2017).

Sixth, our analysis provides an analysis of the performance trajectories of serial crowdfunders on Kickstarter. Although Kickstarter is the world's leading reward-based crowdfunding platform with more than $\$ 4.6$ billion pledged by backers, it cannot be assumed that our results automatically apply to other crowdfunding platforms as well. While there is no reason to believe that Kickstarter is unusual in terms of dynamic fundraising outcomes, future research should try to replicate our results using data from other platforms, to assess their external validity.

To conclude, the evolution of crowdfunding as a context for serial venture launching is attracting growing scholarly attention. This paper provides some early evidence about the fundraising performance of serial crowdfunders over successive campaigns (the 'what') and yields insights into the underlying mechanisms (the 'why'). Further research is needed to provide greater clarity about the external validity of our results and the underlying mechanisms at work, including other implications of dynamic reputation management on crowdfunding platforms.

\section{Appendix A. Theoretical models}

Supplementary data to this article can be found online at https://doi.org/10.1016/j.jbusvent.2021.106124.

\footnotetext{
${ }^{7}$ We are grateful to an anonymous reviewer for this point.
} 


\section{References}

Agrawal, A., Catalini, C., Goldfarb, A., 2015. Crowdfunding: geography, social networks, and the timing of investment decisions. Journal of Economics \& Management Strategy 24 (2), 253-274.

Allison, T.H., Davis, B.C., Webb, J.W., Short, J.C., 2017. Persuasion in crowdfunding: an elaboration likelihood model of crowdfunding performance. J. Bus. Ventur. 32 (6), 707-725.

Al-Sadoon, M.M., Jiménez-Martín, S., Labeaga, J.M., 2019. Simple Methods for Consistent Estimation of Dynamic Panel Data Sample Selection Models (Barcelona Graduate School of Economics Working Papers).

Alsos, G., Kolvereid, L., 1998. The business gestation process of novice, serial, and parallel business founders. Entrepreneurship Theory and Practice 22 (4), $101-114$. Amaral, A.M., Baptista, R., Lima, F., 2011. Serial entrepreneurship: impact of human capital on time to re-entry. Small Bus. Econ. 37 (1), 1-21.

Amit, R., Brander, J., Zott, C., 1998. Why do venture capital firms exist? Theory and Canadian evidence. J. Bus. Ventur. 13 (6), $441-466$.

Ang, A., Piazzesi, M., 2003. A no-arbitrage vector autoregression of term structure dynamics with macroeconomic and latent variables. J. Monet. Econ. 50 (4), $745-787$.

Anglin, A.H., Short, J.C., Drover, W., Stevenson, R.M., McKenny, A.F., Allison, T.H., 2018a. The power of positivity? The influence of positive psychological capital language on crowdfunding performance. J. Bus. Ventur. 33 (4), 470-492.

Anglin, A.H., Wolfe, M.T., Short, J.C., McKenny, A.F., Pidduck, R.J., 2018b. Narcissistic rhetoric and crowdfunding performance: a social role theory perspective. J. Bus. Ventur. 33 (6), 780-812.

Arellano, M., Bond, S., 1991. Some tests of specification for panel data: Monte Carlo evidence and an application to employment equations. Rev. Econ. Stud. 58 (2), 277 .

Atanasov, V., Ivanov, V., Litvak, K., 2012. Does reputation limit opportunistic behavior in the VC industry? Evidence from litigation against VCs. J. Financ. 67 (6), 2215-2246.

Basu, A., Parker, S.C., 2001. Family finance and new business start-ups. Oxf. Bull. Econ. Stat. 63 (3), 333-358.

Belleflamme, P., Lambert, T., Schwienbacher, A., 2013. Individual crowdfunding practices. Ventur. Cap. 15 (4), $313-333$.

Berger, A.N., Udell, G.F., 1995. Relationship lending and lines of credit in small firm finance. J. Bus. 68 (3), $351-381$.

Bernhardt, D., 2000. Credit rationing? Am. Econ. Rev. 90 (1), 235-239.

Berzonsky, M.D., 1994. Self-identity: the relationship between process and content. J. Res. Pers. 28 (4), $453-460$.

Beshears, J., Choi, J.J., Laibson, D., Madrian, B.C., 2017, June 1. Does Aggregated Returns Disclosure Increase Portfolio Risk Taking? Oxford University Press, Review of Financial Studies.

Brancati, E., 2015. Innovation financing and the role of relationship lending for SMEs. Small Bus. Econ. 44 (2), $449-473$.

Burbidge, J.B., Magee, L., Robb, A.L., 1988. Alternative transformations to handle extreme values of the dependent variable. J. Am. Stat. Assoc. 83 (401), 123.

Busenitz, L.W., Barney, J.B., 1997. Differences between entrepreneurs and managers in large organizations: biases and heuristics in strategic decision-making. J. Bus. Ventur. 12 (1), 9-30.

Butticè, V., Colombo, M.G., Wright, M., 2017. Serial crowdfunding, social capital, and project success. Entrepreneurship Theory and Practice 41 (2), $183-207$.

Butticè, V., Orsenigo, C., Wright, M., 2018. The effect of information asymmetries on serial crowdfunding and campaign success. Economia e Politica Industriale 45 (2), 143-173.

Carbonara, E., Tran, H.T., Santarelli, E., 2020. Determinants of novice, portfolio, and serial entrepreneurship: an occupational choice approach. Small Bus. Econ. 55 (1), 123-151.

Chan, C.S.R., Parhankangas, A., Sahaym, A., Oo, P., 2019. Bellwether and the Herd? Unpacking the u-shaped relationship between prior funding and subsequent contributions in reward-based crowdfunding, Journal of Business Venturing.

Chemla, G., Hennessy, C., 2014. Skin in the game and moral hazard. J. Financ. 69 (4), 1597-1641.

Chen, J., 2013. Selection and serial entrepreneurs. Journal of Economics \& Management Strategy 22 (2), $281-311$.

Cholakova, M., Clarysse, B., 2015. Does the possibility to make equity investments in crowdfunding projects crowd out reward-based investments? Entrepreneurship Theory and Practice 39 (1), 145-172.

Chrisman, J.J., McMullan, E., Hall, J., 2005. The influence of guided preparation on the long-term performance of new ventures. J. Bus. Ventur. 20 (6), 769-791.

Clemenz, G. (1986). Credit Markets with Asymmetric Information (Vol. 272). Berlin, Heidelberg: Springer Berlin Heidelberg.

Cochrane, J.H., 1994. Permanent and transitory components of GNP and stock prices. Q. J. Econ. 109 (1), $241-265$.

Colombo, M.G., Franzoni, C., Rossi-Lamastra, C., 2015. Internal social capital and the attraction of early contributions in crowdfunding. Entrepreneurship Theory and Practice 39 (1), 75-100.

Courtney, C., Dutta, S., Li, Y., 2017. Resolving information asymmetry: signaling, endorsement, and crowdfunding success. Entrepreneurship Theory and Practice 41 (2), 265-290.

Cumming, D.J., Leboeuf, G., Schwienbacher, A., 2014. Crowdfunding models: keep-it-all vs. all-or-nothing. SSRN Working Paper No. 2447567 (December 2014), $1-33$.

Davis, B.C., Hmieleski, K.M., Webb, J.W., Coombs, J.E., 2017. Funders' positive affective reactions to entrepreneurs' crowdfunding pitches: the influence of perceived product creativity and entrepreneurial passion. J. Bus. Ventur. 32 (1), 90-106.

Douglas, E.J., Shepherd, D.A., 2000. Entrepreneurship as a utility maximizing response. J. Bus. Ventur. 15 (3), $231-251$.

Douglas, E.J., Shepherd, D.A., 2002. Self-employment as a career choice: attitudes, entrepreneurial intentions, and utility maximization. Entrepreneurship Theory and Practice 26 (3), 81-90.

Drover, W., Busenitz, L., Matusik, S., Townsend, D., Anglin, A., Dushnitsky, G., 2017. A review and road map of entrepreneurial equity financing research: venture capital, corporate venture capital, angel investment, crowdfunding, and accelerators. J. Manag. 43 (6), 1820-1853.

Du, Z., Li, M., Wang, K., 2018. The More Options, the Better? (Investigating the impact of the number of options on backers' decisions in reward-based crowdfunding projects. Information \& Management).

Eggers, J.P., Song, L., 2015. Dealing with failure: serial entrepreneurs and the costs of changing industries between ventures. Acad. Manag. J. 58 (6), 1785-1803.

Ellingsen, T., Kristiansen, E.G., 2011. Financial contracting under imperfect enforcement. Q. J. Econ. 126 (1), $323-371$.

Fairchild, R., 2011. An entrepreneur's choice of venture capitalist or angel-financing: a behavioral game-theoretic approach. J. Bus. Ventur. 26 (3), 359-374.

Flannery, M.J., Hankins, K.W., 2013. Estimating dynamic panel models in corporate finance. J. Corp. Finan. 19, 1-19.

Franke, G.R., Richey, R.G., 2010. Improving generalizations from multi-country comparisons in international business research. J. Int. Bus. Stud. 41 (8), $1275-1293$.

Frydrych, D., Bock, A.J., Kinder, T., Koeck, B., 2014. Exploring entrepreneurial legitimacy in reward-based crowdfunding. Ventur. Cap. 16 (3), $247-269$.

Gervais, S., Goldstein, I., 2007. The positive effects of biased self-perceptions in firms. Review of Finance 11, 453-496.

Ghatak, M., Guinnane, T.W., 1999. The economics of lending with joint liability: theory and practice. J. Dev. Econ. 60 (1), $195-228$.

Ghatak, M., Morelli, M., Sjostrom, T., 2001. Occupational choice and dynamic incentives. Rev. Econ. Stud. 68 (4), $781-810$.

Gompers, P.A., 1996. Grandstanding in the venture capital industry. J. Financ. Econ. 42 (1), 133-156.

Gompers, P., Kovner, A., Lerner, J., 2009. Specialization and success: evidence from venture capital. Journal of Economics \& Management Strategy 18 (3), $817-844$.

Gompers, P., Kovner, A., Lerner, J., Scharfstein, D., 2010. Performance persistence in entrepreneurship. J. Financ. Econ. 96 (1), $18-32$.

Hair, J.F., Black, W.C., Babin, B.J., Anderson, R.E., 2010. Multivariate Data Analysis, 7th ed. (Pearson).

Hervé, F., Schwienbacher, A., 2018. Crowdfunding and innovation. J. Econ. Surv. 32 (5), 1514-1530.

Hessels, J., Grilo, I., Thurik, R., van der Zwan, P., 2011. Entrepreneurial exit and entrepreneurial engagement. J. Evol. Econ. 21 (3), $447-471$.

Hsiao, C., 2014. Analysis of Panel Data, 3rd ed. Cambridge University Press.

Kaplan, S., 2003. Financial contracting theory meets the real world: evidence from venture capital contracts. Review of Economic Studies 70 (2), 281-315.

Kaplan, S.N., Strömberg, P., 2001. Venture capitalists as principals: contracting, screening, and monitoring. Am. Econ. Rev. 91 (2), $426-430$. 
Kautonen, T., Kibler, E., Minniti, M., 2017. Late-career entrepreneurship, income and quality of life. J. Bus. Ventur. 32 (3), $318-333$.

Keuschnigg, C., Nielsen, S.B., 2004. Start-ups, venture capitalists, and the capital gains tax. J. Public Econ. 88 (5), $1011-1042$.

Keuschnigg, C., \& Nielsen, S. B. (2006). Public policy, start-up entrepreneurship and the market for venture capital. In The Life Cycle of Entrepreneurial Ventures (pp. 227-257). Springer US.

Kunz, M.M., Bretschneider, U., Erler, M., Leimeister, J.M., 2017. An empirical investigation of signaling in reward-based crowdfunding. Electron. Commer. Res. 17 (3), 425-461.

Kuppuswamy, V., Bayus, B.L., 2017. Does my contribution to your crowdfunding project matter? J. Bus. Ventur. 32 (1), $72-89$.

Kuppuswamy, V., Mollick, E.R., 2016. Second Thoughts about Second Acts: Gender Differences in Serial Founding Rates (SSRN Electronic Journal).

Lagazio, C., Querci, F., 2018. Exploring the multi-sided nature of crowdfunding campaign success. J. Bus. Res. 90, $318-324$.

Landier, A., Thesmar, D., 2009, January 1. Financial Contracting with Optimistic Entrepreneurs. Review of Financial Studies, Oxford Academic.

Lee, C.H., Chiravuri, A., 2019. Dealing with initial success versus failure in crowdfunding market: serial crowdfunding, changing strategies, and funding performance. Internet Res. 29 (5), 1190-1212.

Li, E., Martin, J.S., 2019. Capital formation and financial intermediation: the role of entrepreneur reputation formation. J. Corp. Finan. 59, 185-201.

Lin, M., Viswanathan, S., 2016. Home bias in online investments: an empirical study of an online crowdfunding market. Manag. Sci. 62 (5), 1393-1414.

Mailath, G.J., Samuelson, L., 2001. Who wants a good reputation? Rev. Econ. Stud. 68 (2), 415-441.

Manove, M., Padilla, A.J., 1999. Banking (conservatively) with optimists. RAND J. Econ. 30 (2), 324.

McDonald, J.F., Moffitt, R.A., 1980. The uses of tobit analysis. Rev. Econ. Stat. 62 (2), 318.

McMillan, J., Woodruff, C., 1999. Interfirm relationships and informal credit in Vietnam. Q. J. Econ. 114 (4), $1285-1320$.

de Meza, D., Gould, J.R., 1992. The social efficiency of private decisions to enforce property rights. J. Polit. Econ. 100 (3), 561-580.

de Meza, D., Webb, D.C., 1987. Too much investment: a problem of asymmetric information. Q. J. Econ. 102 (2), 281.

de Meza, D., Webb, D., 1990. Risk, adverse selection and capital market failure. Econ. J. 100 (399), 206.

Mollick, E., 2014. The dynamics of crowdfunding: an exploratory study. J. Bus. Ventur. 29 (1), 1-16.

Nahata, R., 2008. Venture capital reputation and investment performance. J. Financ. Econ. 90 (2), 127-151.

Nahata, R., 2019. Success is good but failure is not so bad either: serial entrepreneurs and venture capital contracting. J. Corp. Finan. 58, $624-649$.

Neter, J., Wasserman, W., \& Kutner, M. (2018). Applied linear statistical models : regression, analysis of variance, and experimental designs. SERBIULA (Sistema Librum 2.0).

Nickell, S., 1981. Biases in dynamic models with fixed effects. Econometrica 49 (6), 1417.

Parhankangas, A., Renko, M., 2017. Linguistic style and crowdfunding success among social and commercial entrepreneurs. J. Bus. Ventur. 32 (2), 215-236.

Parker, S.C., 1996. A time series model of self-employment under uncertainty. Economica 63 (251), 459.

Parker, S.C., 2006. Learning about the unknown: how fast do entrepreneurs adjust their beliefs? J. Bus. Ventur. 21 (1), 1-26.

Parker, S.C., 2009. Can cognitive biases explain venture team homophily? Strateg. Entrep. J. 3 (1), 67-83.

Parker, S.C., 2013. Do serial entrepreneurs run successively better-performing businesses? J. Bus. Vent. 28 (5), $652-666$.

Parker, S.C., 2014. Who become serial and portfolio entrepreneurs? Small Bus. Econ. 43 (4), 887-898.

Parker, S.C., 2018. The Economics of Entrepreneurship. Cambridge University Press, The Economics of Entrepreneurship.

Petersen, M.A., Rajan, R.G., 1994. The benefits of lending relationships: evidence from small business data. J. Financ. 49 (1), $3-37$.

Poczter, S., Shapsis, M., 2018. Gender disparity in angel financing. Small Bus. Econ. 51 (1), 31-55.

Puri, M., Robinson, D.T., 2007. Optimism and economic choice. J. Financ. Econ. 86 (1), 71-99.

Sargan, J.D., 1958. The estimation of economic relationships using instrumental variables. Econometrica 26 (3), 393.

Sauerwald, S., Lin, Z.J., Peng, M.W., 2016. Board social capital and excess CEO returns. Strateg. Manag. J. 37 (3), $498-520$.

Scheaf, D.J., Davis, B.C., Webb, J.W., Coombs, J.E., Borns, J., Holloway, G., 2018. Signals' flexibility and interaction with visual cues: insights from crowdfunding. J. Bus. Ventur. 33 (6), 720-741.

Schmidt, K.M., 2003, June 1. Convertible Securities and Venture Capital Finance. John Wiley \& Sons, Ltd., Journal of Finance.

Schwienbacher, A., 2018. Entrepreneurial risk-taking in crowdfunding campaigns. Small Bus. Econ. 51 (4), 843-859.

Shan, J., 2005. Does financial development "lead" economic growth? A vector auto-regression appraisal. Appl. Econ. 37 (12), $1353-1367$.

Sieger, P., Minola, T., 2017. The family's financial support as a "poisoned gift": a family embeddedness perspective on entrepreneurial intentions. J. Small Bus. Manag. 55, 179-204.

Skirnevskiy, V., Bendig, D., Brettel, M., 2017. The influence of internal social capital on serial creators' success in crowdfunding. Entrepreneurship Theory and Practice 41 (2), 209-236.

Smith, B., Viceisza, A., 2018. Bite me! ABC's Shark Tank as a path to entrepreneurship. Small Bus. Econ. 50 (3), $463-479$.

Stiglitz, J.E., Weiss, A., 1981. Credit rationing in markets with imperfect information. Am. Econ. Rev. 71 (3), 393-410.

Tabachnick, B.G., Fidell, L.S., 2007. Using Multivariate Statistics (Pearson/Allyn \& Bacon).

Uchida, H., Udell, G.F., Yamori, N., 2012. Loan officers and relationship lending to SMEs. J. Financ. Intermed. 21 (1), 97-122.

Viotto da Cruz, J., 2018. Beyond financing: crowdfunding as an informational mechanism. J. Bus. Ventur. 33 (3), $371-393$.

Watson, H., 1984. Credit markets and borrower effort. South. Econ. J. 50 (3), 802.

Wernerfelt, B., 1988. Reputation, monitoring, and effort. Inf. Econ. Policy 3 (3), 207-218.

Williamson, S.D., 1987. Costly monitoring, loan contracts, and equilibrium credit rationing. Q. J. Econ. 102 (1), 135.

Wooldridge, J.M., 2005. Simple solutions to the initial conditions problem in dynamic, nonlinear panel data models with unobserved heterogeneity. J. Appl. Econ. 20 (1), 39-54.

Yang, L., Hahn, J., 2015. Learning from Prior Experience: An Empirical Study of Serial Entrepreneurs in IT-Enabled Crowdfunding (ICIS).

Zhang, J., 2011. The advantage of experienced start-up founders in venture capital acquisition: evidence from serial entrepreneurs. Small Bus. Econ. 36 (2), 187-208.

Zhang, L., 2019. Founders matter! Serial entrepreneurs and venture capital syndicate formation. Entrepreneurship Theory and Practice 43 (5), 974-998.

Zhang, H., Chen, W., 2019. Crowdfunding technological innovations: interaction between consumer benefits and rewards. Technovation 84-85, 11-20.

Zhang, W., Yan, X., Chen, Y., 2017. Configurational path to financing performance of crowdfunding projects using fuzzy set qualitative comparative analysis. Eng. Econ. 28 (1), 25-34. 